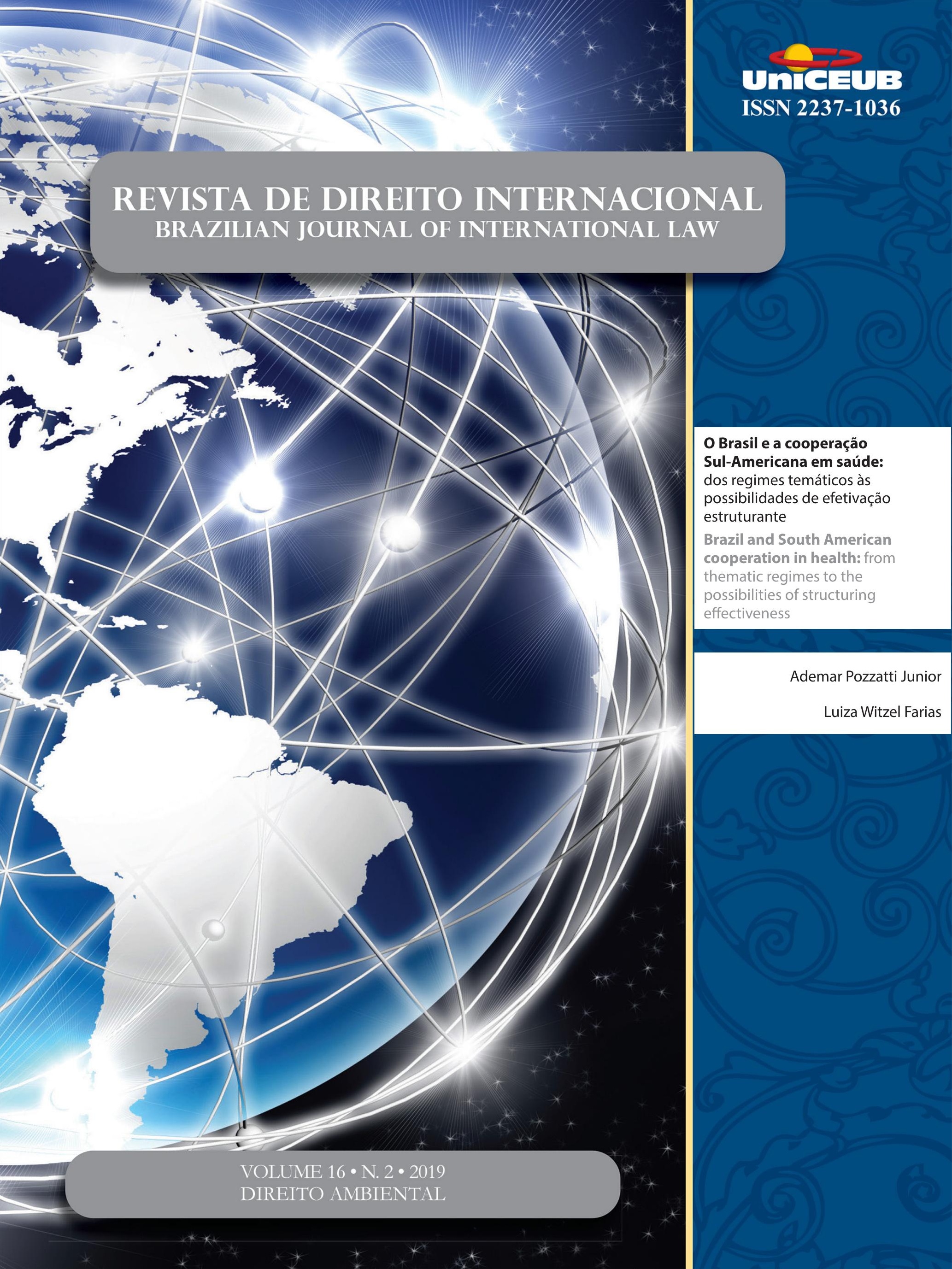




\section{Sumário}

I. Crônicas do Direito Internacional .................................................1

AMAZONIE: LE DROIT INTERNATIONAL EN VIGUEUR APPORTE DES RÉPONSES SUBSTANTIELLES ... 3 Pierre-Marie Dupuy

A eVOluÇão da SOluÇão DE CONTROVÉRSias NOS ACFIs 8 Ana Rachel Freitas da Silva

II. Dossiê Especial: Direito ambientai 14

A brief overview of Sustainable DeVelopment: HOW A DEBATEd CONCEPT With A MUCH-CONTESTED LEGAL NATURE COULD PERFORM A VALUABLE ROLE IN THE DECISION-MAKING ......16 Natali Francine Cinelli Moreira

A meta 11 de Aichi e as Áreas marinhas protegidas em grande ESCALA: proteção ambienTAL OU OPORTUNISMO POLÍTICO?

Alexandre Pereira da Silva

LITIGÂNCIA CLIMÁTICA COMO ESTRATÉGIA JURISDICIONAL AO AQUECIMENTO GLOBAL ANTROPOGÊNICO E MUDANÇAS CLIMÁTICAS

Délton Winter de Carvalho e Kelly de Souza Barbosa

AsSESSMENT AND CHALlENGES OF CARBON MARKETS

Louise Pigeolet e Arnaud Van Waeyenberge

As abordagens dos países da América Latina e Caribe sobre a mobilidade humana proVOCADA PELAS MUDANÇAS CLIMÁTICAS

Diogo Andreola Serraglio e Heline Sivini Ferreira

Implementation of Legal mechanisms of environmental protection by the South PaCIFIC REGIONAL ORGANIZATIONS 116 Joanna Siekiera 
CONCILIATING THE OVERLAP OF PROTECTED AREAS AND TRADITIONAL TERRITORIES: LEGAL INNOVATIONS FOR BIOLOGICAL DIVERSITY CONSERVATION IN BRAZILIAN PARKS

Nathalia Fernandes Lima e Solange Teles Silva

O USO DE DRONES COMO INSTRUMENTO PARA A CONSERVAÇÃo DA BIODIVERSIDADE NO BRASIL141 Larissa Suassuna Carvalho Barros e Marcia Dieguez Leuzinger

Agrotóxicos e direitos humanos no contexto global: o Brasil EM Risco de Retrocesso?

Marcelo Pretto Mosmann, Letícia Albuquerque e Isabele Bruna Barbieri

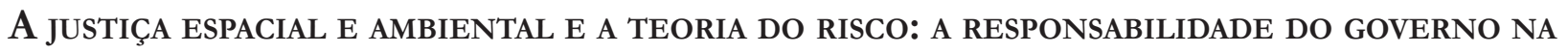
PREVENÇÃo CONTRA DESASTRES (NO BRASIL). 169

José Adércio Leite Sampaio e Edson Rodrigues de Oliveira

The judgment of the case Xucuru People v. Brazil: Inter-American Court of Human RigHTS BETWEEN CONSOLIDATION AND SETBACKS

Gabriela Cristina Braga Navarro

II. Artigos sobre outros temas

NACIONALIDADE: NOVAS REGRAS, VELHOS PROBLEMAS

226

Paulo Henrique Faria Nunes

O EXERCíCIO DA JURISDIÇÃO INTERAMERICANA DE DIREITOS HUMANOS: LEGITIMIDADE, PROBLEMAS E POSSÍVEIS SOLUÇÕES

Felipe Grizotto Ferreira, Guilherme Perez Cabrale Lucas Catib de Laurentiis

A proteção da identidade de gênero na jurisprudênCia da Corte Europeia de Direitos Humanos

Gabriel Coutinho Galil

O COMITÊ JURÍdico INTERAMERICANO dA OEA E A CODIFICAÇÃo DO DIREITO INTERNACIONAL REGIONAL. 
O caso Petruhhin e o princípio do nível mais elevado de proteção no tocante aos diREITOS FUNDAMENTAIS NO ÂMBITO DA UNIÃo EUROPEIA............................................304

Clovis Demarchi e Jaine Cristina Suzin

A AUTONOMia da VONTADE NA ESCOLHA dA LEI APLICÁVEl AOS CONTRATOS DE COMÉRCiO INTER-

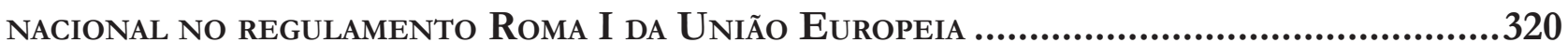

Aline Beltrame de Moura e Rafaela Hörmann

A JuRisdição da ICANN: desafios atuais e Prospectivas futuras...............................335 Aziz Tuffi Saliba e Amael Notini Moreira Bahia

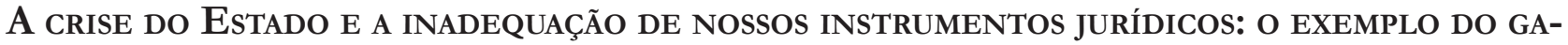
RANTISMO PENAL NO BRASIL.

Oswaldo Poll Costa e Francisco Quintanilha Veras Neto

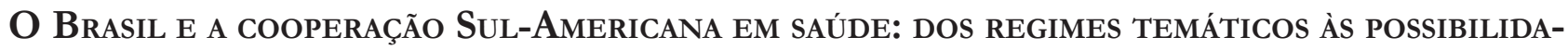
DES DE EFETIVAÇÃo ESTRUTURANTE

Ademar Pozzatti Junior e Luiza Witzel Farias

III. RESENHAS

Resenha da obra: SILVA, Waldimeiry Correa da. Regime internacional de enfrentaMENTO AO TRÁFICO DE PESSOAS: AVANÇOS E DESAFIOS PARA A PROTEÇÃo DOS DIREITOS HUMANOS. Rio de Janeiro: Lumen Juris, 2018. 385

Mércia Cardoso de Souza e Guirino Nhatave 


\title{
O Brasil e a cooperação Sul-Americana em saúde: dos regimes temáticos às possibilidades de efetivação estruturante*
}

\author{
Brazil and South American cooperation \\ in health: from thematic regimes to the \\ possibilities of structuring effectiveness
}

\author{
Ademar Pozzatti Junior** \\ Luiza Witzel Farias***
}

\section{Resumo}

A cooperação internacional que se propõe estruturante é interpretada sob duas dimensões, ambas permeadas por um direito internacional contemporâneo que busca se tornar efetivo no âmbito doméstico. Na primeira dimensão, essa abordagem da cooperação toma a forma de atos internacionais, e, na segunda, de políticas públicas domésticas. Este artigo foca na primeira dimensão da cooperação estruturante em saúde, teorizada por pesquisadores ligados à Fundação Oswaldo Cruz, no Brasil. O trabalho se propõe ao estudo empírico dos atos internacionais firmados pelo Estado brasileiro com os demais Estados da América do Sul, em matéria de saúde e em vigor, para averiguar a existência e o estado da arte de regimes temáticos dedicados à efetivação do direito humano à saúde, bem como suas possibilidades de efetivação estruturante. Além disso, o trabalho localiza a abordagem brasileira da saúde internacional nas agendas internacionais que se verificam historicamente no setor saúde. Para esses fins, são utilizados os resultados quantificados de um extenso levantamento documental, capazes de comprovar a existência dos regimes temáticos, e que estes são permeados por possibilidades de efetivação estruturante, situando a abordagem brasileira em uma agenda mista e inovadora.

* Recebido em 21/02/2019

Aprovado em 21/08/2019

Pesquisa financiada com recursos do Edital Universal 2016 do CNPQ, Processo número 423592/2016-5.

** Professor do Programa de Pós-Graduação em Direito (PPGD) e do Programa de Pós-Graduação em Relações Internacionais (PPGRI) da Universidade Federal de Santa Maria (UFSM), onde coordena o Núcleo de Pesquisa e Práticas em Direito Internacional (NPPDI). E-mail: ademar.pozzatti@ufsm.br

*** Estudante do Curso de Relações Internacionais da Universidade Federal de Santa Maria (UFSM), pesquisadora do Núcleo de Pesquisa e Práticas em Direito Internacional (NPPDI).E-mail: luwfarias@gmail.com

Palavras-Chave: cooperação internacional em saúde; direito internacional; direitos humanos.

\section{Abstract}

In this paper, the international cooperation that is proposed structuring it is interpreted under two dimensions, permeated by contemporary international law, which seeks to become effective in the domestic sphere. In the first dimension this approach to cooperation takes the form of international treaties, and in the second, domestic public policies. This article focuses on the first dimension of structuring cooperation in health, theorized by researchers linked to the Oswaldo Cruz Foundation in Brazil. It proposes the empirical study of the international acts signed by the Brazilian State with the 
other States of South America in health and in force, to investigate the existence and state of the art of thematic regimes dedicated to the realization of the human right to health, as well as its possibilities of structuring effectiveness. In addition to locating the Brazilian approach to international health in the international agendas that have occurred historically in the health sector. For these purposes, are utilized the quantified results of an extensive documentary survey, capable of proving the existence of thematic regimes, and that these are permeated by possibilities of structuring effectiveness, placing the Brazilian approach in a mixed and innovative agenda.

Keywords: international cooperation in health; international law; human rights.

\section{Introdução}

A realização dos direitos humanos, no âmbito de documentos de cunho universal, notadamente na Carta das Nações Unidas, de 1945, possui como instrumento imprescindível a cooperação internacional ${ }^{1}$. Nesse mesmo âmbito universal, o direito humano à saúde foi primeira e indiretamente reconhecido pela Declaração Universal dos Direitos Humanos, de 1948, e em seguida pelo Pacto Internacional sobre Direitos Civis e Políticos, de 1966, ainda indiretamente, em decorrência ou reforço ao direito à vida. Tendo sido diretamente reconhecido apenas por meio do Pacto Internacional sobre Direitos Econômicos, Sociais e Culturais, também de 1966, que passa a reconhecer o direito a saúde como um direito social, na medida em que a sua realização demanda mais ação do que abstenção estatal ${ }^{2}$.

Principalmente, no caso dos países em desenvolvimento, há, às vezes, a incapacidade dos Estados de prover o direito à saúde de modo efetivo ${ }^{3}$, seja por questões

\footnotetext{
1 POZZATTI JÚNIOR, Ademar. Cooperação Internacional como Acesso à Justiça nas Relações Internacionais: os desafios do direito brasileiro para a implementação de uma cultura cosmopolita. 2015. Tese (Doutorado)-Programa de Pós-Graduação em Direito Universidade Federal de Santa Catarina, Florianópolis, 2015.

2 TORRONTEGUY, Marco Aurélio Antas. O direito humano à saúde no direito internacional: efetivação por meio da cooperação sanitária. 2010. Tese (Doutorado) - Faculdade de Direito da USP, São Paulo, 2010.

3 TORRONTEGUY, Marco Aurélio Antas. O direito humano à saúde no direito internacional: efetivação por meio da cooperação sanitária. 2010. Tese (Doutorado) - Faculdade de Direito, Universi-
}

estruturais diversas, como a falta de recursos financeiros e humanos, seja porque os problemas que demandam as ações estatais são de ordem transnacional ${ }^{4}$ e não podem ser resolvidos de maneira unilateral. Nesse sentido, percebe-se a proeminência da cooperação internacional como instrumento de garantia de direitos.

Tendo em vista esse contexto, a presente pesquisa busca verificar a existência e o estado da arte de regimes temáticos de cooperação internacional destinados à efetivação do direito humano à saúde, desenvolvidos pelo Brasil com os demais países da América do Sul, bilateral e multilateralmente, por meio da análise dos atos internacionais firmados entre os governos desses países, e que estão vigentes atualmente. Além disso, tendo como ponto de partida a abordagem da cooperação estruturante em saúde, desenvolvida por pesquisadores da Fundação Oswaldo Cruz (Fiocruz), no Brasil, busca-se, por meio da quantificação desses regimes, identificar como a cooperação brasileira em saúde se situa na agenda internacional destinada a esse setor e, por meio da análise e quantificação das categorias de cooperação estruturante presentes ou não nos atos internacionais, compreender as possibilidades de efetivação estruturante desses regimes. Para esses fins, são empregados extenso levantamento documental, quantificação dos dados colhidos e análise qualitativa da estrutura e do conteúdo desses atos.

A escolha pela região da América do Sul é justificada, principalmente, pelo berço geográfico da prática da cooperação estruturante em saúde, que é teorizada pelos pesquisadores da Fiocruz no mesmo período em que é objeto de trabalho na União das Nações Sul-Americanas (Unasul), evidenciando a região como primeiro eixo de produção normativa no modelo. Na Unasul, a cooperação estruturante torna-se modus operandi para redes intergovernamentais - uma das principais estratégias do modelo, para o fortalecimento de sistemas de saúde - como se verifica na Resolução 07/2009 do Conselho de Saúde da Unasul, que determina a criação de redes de intercâmbio entre instituições que promovem a formação de pessoal para os sistemas de saúde dos países da região ${ }^{5}$. De modo que, é esperado encon-

dade de São Paulo, São Paulo, 2010.

4 SLAUGHTER, Anne-Marie; BURKE-WHITE, William. The Future of International Law is Domestic (or, The European Way of Law). Harvard International Law Journal, Cambridge, v. 47, n. 2 , jun. 2006.

5 UNIÃO DAS NAÇÕES SUL-AMERICANAS. Consejo de 
trar alguma densidade de atos com possibilidades de efetivação estruturante por meio dessa escolha.

O trabalho é dividido em três partes, além da introdução e das considerações finais. A primeira parte corresponde a um debate que situa a cooperação estruturante teoricamente, bem como constrói o caminho pelo qual ela pode se tornar efetiva, além de situá-la dentro da agenda internacional da saúde. Essa parte mostra como a cooperação estruturante pode efetivar o direito humano à saúde. A segunda parte apresenta o levantamento de atos internacionais, e, por meio das dimensões quantitativas e geográficas dos regimes formados, ela é responsável por dizer, empiricamente, quais são os interesses brasileiros e sul-americanos em termos de efetivação do direito humano à saúde na região. A terceira parte, ao observar a quantificação das categorias de cooperação sul-sul e estruturante presentes ou não nos atos, trata da identificação das possibilidades de efetivação estruturante, sendo responsável por relatar empiricamente, de que modo - ou por meio de quais ideias — o Brasil pretende realizar os compromissos assumidos com relação ao direito humano à saúde. Ainda, apesar dos objetivos assumidos, não se descartam outras lições que possam surgir quando da análise combinada do debate teórico, da revisão bibliográfica, e do acervo de atos coletados.

\section{Do nascimento à emancipação do direito humano: o caso da cooperação estruturante em saúde}

Para Slaughter e Burke-White ${ }^{6}$, o direito internacional passa na atualidade por uma reorganização dos meios e mecanismos por meio dos quais opera. Isso porque, se as regras respondem a problemas concretos, e há uma nova geração de problemas mundiais, que surgem de dentro dos estados e não da sua ação interestatal, "para oferecer uma resposta eficaz a esses novos desafios, o sistema jurídico internacional deve ser capaz de influenciar as políticas domésticas dos Estados e aproveitar as

Salud. Resolución 07/2009. Guayaquil, Ecuador, 24 nov. 2009. Disponível em: http://www.rets.epsjv.fiocruz.br/sites/default/files/ arquivos/unasul-saude_res072009.pdf Acesso em: 05 jun. 2019.

6 SLAUGHTER, Anne-Marie; BURKE-WHITE, William. The Future of International Law is Domestic (or, The European Way of Law). Harvard International Law Journal, Cambridge, v. 47, n. 2, jun. 2006. instituições nacionais na busca de objetivos globais"”. Para tanto, o direito internacional possui três formas distintas: fortalecer as instituições domésticas, subsidiá-las, quando da sua inércia, e compeli-las a agir.

A cooperação estruturante em saúde, abordagem desenvolvida por pesquisadores ligados à Fiocruz, no Brasil, parece corresponder à primeira forma pela qual o direito internacional influencia as políticas domésticas - o fortalecimento institucional — pois se refere a uma forma de cooperação internacional

centrada no fortalecimento institucional dos sistemas de saúde dos países parceiros, combinando intervenções concretas com a construção de capacidades locais e a geração de conhecimento, e ainda promovendo o diálogo entre atores, de forma a possibilitar que eles assumam o protagonismo na liderança dos processos no setor saúde e promovam a formulação autônoma de uma agenda para o desenvolvimento futuro na saúde. ${ }^{8}$

Apesar de distintas, as três formas pelas quais o direito internacional interage com o âmbito doméstico podem relacionar-se. Conforme afirmam Slaughter e Burke-White:

As normas e instituições jurídicas internacionais podem aumentar a capacidade e a eficácia das instituições domésticas. Se adequadamente projetadas e estruturadas, elas podem ajudar a apoiar grupos políticos e jurídicos domésticos que tentam cumprir as obrigações jurídicas internacionais. Finalmente, elas podem até mesmo forçar ou ordenar ações no nível nacional em resposta a uma ameaça global. ${ }^{9}$

Por dedicar-se ao fortalecimento de instituições estruturantes, que seriam, em última escala, capacitadas para a formulação autônoma de políticas públicas locais, a cooperação estruturante em saúde abre espaço para o entendimento de que, quando fortalecidas, as instituições domésticas seriam também capazes de atuar como os primeiros atores a se lançarem na resolução

SLAUGHTER, Anne-Marie; BURKE-WHITE, William. The Future of International Law is Domestic (or, The European Way of Law). Harvard International Law Journal, Cambridge, v. 47, n. 2, jun. 2006. p. 328

8 ALMEIDA, Celia; CAMPOS, Rodrigo Pires de; BUSS, Paulo; FERREIRA, José Roberto; FONSECA, Luiz Eduardo. A concepção brasileira de cooperação Sul-Sul estruturante em saúde". Revista Eletrônica de Comunicação, Informação e Inovação em Saúde. Rio de Janeiro, v.4, p. 25-35, mar. 2010. p. 28.

9 SLAUGHTER, Anne-Marie; BURKE-WHITE, William. The Future of International Law is Domestic (or, The European Way of Law). Harvard International Law Journal, Cambridge, v. 47, n. 2, jun. 2006. p. 333. 
das outras duas formas que o direito internacional possui para envolver-se nos processos políticos domésticos. As instituições estruturantes em saúde, além de serem entendidas como "pilares para a criação, a sustentação e o aperfeiçoamento de políticas públicas na área da saúde" ${ }^{\prime 10}$, também são

aquelas que têm: capacidade de operacionalizar sistemas e serviços de saúde de maneira efetiva, eficiente e sustentável, em especial através do seu poder oficial; capacidade de gestão e de prestação de serviços de saúde (Ministérios da Saúde, por exemplo); e aptidão de treinamento de profissionais de saúde e geração de dados úteis para a tomada de decisão, através de P\&D e do treinamento dos recursos humanos essenciais para o campo da saúde (institutos nacionais de saúde, escolas de saúde pública, escolas técnicas de saúde, outros institutos e escolas de graduação em saúde, por exemplo). ${ }^{11}$

E, apesar de se situar "no panorama do que hoje vem sendo aplicado como capacity building por estar direcionada para o treinamento de recursos humanos e a construção de capacidades"12, a cooperação estruturante em saúde inova em, pelo menos, duas questões principais:

a) integra o desenvolvimento de recursos humanos com o organizacional e institucional e b) parte da exploração dos recursos e capacidades endógenas de cada país para que os próprios atores locais possam assumir a liderança necessária para a formulação de uma futura agenda de desenvolvimento da saúde e sua implementação sustentável. ${ }^{13}$

Essas inovações, além de reforçarem a localização da cooperação estruturante em saúde no referencial de fortalecimento institucional de Slaughter e Burke-White ${ }^{14}$, também elevam as possibilidades de cooperação a uma perspectiva diferente e em algum grau nova: trata-se de uma perspectiva pós-colonial. Ora, a construção de ca-

10 FERREIRA, José Roberto; FONSECA, Luiz Eduardo. Cooperação estruturante, a experiência da Fiocruz. Revista Ciência \& Saúde Coletiva, v. 22, n. 7, p. 2129-2133, jul. 2017. p. 2130.

11 BUSS, Paulo Marchiori.; FERREIRA, José Roberto. Cooperação e integração regional em saúde na América do Sul: a contribuição da Unasul Saúde. Revista Ciência \& Saúde Coletiva, Rio de Janeiro, v. 16, n. 6, p. 2699-2711, jun. 2011. p. 2706-2707.

12 FERREIRA, José Roberto; FONSECA, Luiz Eduardo. Cooperação estruturante, a experiência da Fiocruz. Revista Ciência \& Saúde Coletiva, v. 22, n. 7, p. 2129-2133, jul. 2017. p. 2130.

13 FERREIRA, José Roberto; FONSECA, Luiz Eduardo. Cooperação estruturante, a experiência da Fiocruz. Revista Ciência \& Saúde Coletiva, v. 22, n. 7, p. 2129-2133, jul. 2017. p. 2131.

14 SLAUGHTER, Anne-Marie; BURKE-WHITE, William. The Future of International Law is Domestic (or, The European Way of Law). Harvard International Law Journal, Cambridge, v. 47, n. 2, jun. 2006. pacidades ao partir de recursos endógenos - instituições e práticas locais pré-existentes —, e não apenas da perspectiva de que países em níveis mais altos de desenvolvimento estão aptos a fortalecer países em níveis mais baixos, relegando a estes seu conjunto de concepções institucionais como herança da ação, carrega consigo uma mediação possível da dicotomia universalismo versus particularismo que permeia os direitos humanos.

Para Pozzatti Júnior ${ }^{15}$, a razão prática de base kantiana impõe um dever de cooperação internacional para a realização política do cosmopolitismo, e portanto, dos direitos humanos. A realização da cooperação que explora recursos e capacidades endógenas, em vez da criação de novas instituições nacionais, ou da mudança destas e das práticas que as identificam sem a existência de um diálogo horizontal, apesar de se apoiar no compartilhamento de determinados valores comuns — notadamente a compreensão da saúde como direito humano - , se apresenta não somente na seara dessa deliberação prática destinada à ação política efetiva e democrática, mas também daquilo que Lucas ${ }^{16}$ chama de diálogo intercultural, em que se deposita a legitimidade ética e força política dos direitos humanos, e para o qual a universalidade dos direitos humanos

não se trata de uma universalização uniformizadora,
mas sim de uma 'universalidade moderada', que
poderá mediar as diferenças e servir de ponto
de partida ético para uma cultura de tolerância
e de emancipação que reconheça as identidades
sem ofuscar e negar aquilo que é reclamado pela
condição humana universal, por todos os povos e
por todas as culturas. ${ }^{17}$

Quanto à agenda internacional da saúde, a bibliografia especializada demonstra a existência de oscilações temáticas. Desde a primeira conferência sanitária internacional, em 1851, até meados da década de 1950, as iniciativas internacionais em matéria de saúde estavam principalmente ligadas a doenças infecciosas e o seu tratamento, além da centralidade das suas interferências

15 POZZATTI JÚNIOR, Ademar. O direito internacional entre o dever ético e a ação política: os fundamentos de um dever de cooperação internacional na filosofia política de Immanuel Kant. Revista de Direito Internacional, Brasília, v. 13, n. 3, p. 405-421, 2016.

16 LUCAS, Doglas Cesar. Multiculturalismo e o debate entre liberais e comunitaristas: em defesa da Interculturalidade dos Direitos Humanos. Revista Sequência, Florianópolis, v. 30, n. 58, p. 101-130, jul. 2009.

17 LUCAS, Doglas Cesar. Multiculturalismo e o debate entre liberais e comunitaristas: em defesa da Interculturalidade dos Direitos Humanos. Revista Sequência, Florianópolis, v. 30, n. 58, p. 101-130, jul. 2009. p. 123. 
no comércio. ${ }^{18}$ Enquanto, "nas décadas de 1960 e 1970, influenciada pelos movimentos alternativos e dos países não alinhados, a cooperação internacional em saúde estava focada na construção de sistemas de saúde baseados na atenção primária à saúde"19, além da introdução das questões da força de trabalho em saúde, tanto por uma agenda global, via Organização Mundial da Saúde (OMS), quanto regional, via Organização Pan-americana da Saúde (OPAS), nas Américas ${ }^{20}$.

Essas duas últimas temáticas, tendo sido resgatadas nos anos 2000, dada a precarização dos sistemas de saúde dos países em desenvolvimento, resultado das crises econômicas globais dos anos 1980 e 1990, da disseminação das reformas promovidas pelos ideais neoliberais, decorrente da crise do modelo de bem-estar social, e de uma cooperação internacional em saúde marcada principalmente por intervenções tecnológicas e de produtos.

A partir dessas oscilações, pode-se inferir que existem duas agendas concorrentes - que correspondem a ideias e interesses de grupos diferentes de atores - e que se intercalam de tempos em tempos. Para uma delas, importa resolver epidemias específicas que podem afetar os países desenvolvidos em termos econômicos e securitários. ${ }^{21}$ Essa agenda pode ser pensada como a tradução dos interesses em saúde dos países do Norte social, uma agenda Norte-Sul ou vertical. A segunda agenda está preocupada em fortalecer sistemas locais de saúde - tanto em termos de organização, quanto de pessoal - e portanto, com variáveis menos efêmeras

18 ALMEIDA, Celia. Saúde, política externa e cooperação sulsul em saúde: elementos para a reflexão sobre o caso do Brasil. In: FUNDAÇÃO OSWALDO CRUZ. A saúde no Brasil em 2030 - prospecção estratégica do sistema de saúde brasileiro: desenvolvimento, Estado e políticas de saúde. Rio de Janeiro: Fiocruz/ Ipea/Ministério da Saúde/Secretaria de Assuntos Estratégicos da Presidência da República, 2013.

19 ALMEIDA, Celia; CAMPOS, Rodrigo Pires de; BUSS, Paulo; FERREIRA, José Roberto; FONSECA, Luiz Eduardo. A concepção brasileira de cooperação Sul-Sul estruturante em saúde". Revista Eletrônica de Comunicação, Informação e Inovação em Saúde, Rio de Janeiro, v.4, p. 25-35, mar. 2010. p. 27.

20 ALMEIDA, Celia. Saúde, política externa e cooperação sulsul em saúde: elementos para a reflexão sobre o caso do Brasil. In: FUNDAÇÃO OSWALDO CRUZ. A saúde no Brasil em 2030 - prospecção estratégica do sistema de saúde brasileiro: desenvolvimento, Estado e políticas de saúde. Rio de Janeiro: Fiocruz/ Ipea/Ministério da Saúde/Secretaria de Assuntos Estratégicos da Presidência da República, 2013.

21 FERREIRA, José Roberto; FONSECA, Luiz Eduardo. Cooperação estruturante, a experiência da Fiocruz. Revista Ciência \& Saúde Coletiva, v. 22, n. 7, p. 2129-2133, jul. 2017. que a eclosão de doenças específicas, parecendo mais próxima do interesse na efetivação do direito humano à saúde, em longo prazo.

Essa segunda agenda, passou a fazer parte da pauta internacional de saúde apenas nas décadas das descolonizações - 1960 e 1970 - quando os novos Estados em desenvolvimento passaram a organizar-se coletivamente e diagnosticar com maior autonomia as suas próprias demandas. Assim, esta agenda pode ser pensada como a tradução das demandas desse grupo de países, parecendo-se, então, mais como uma agenda do Sul para o Sul, ou horizontal. E, pode-se afirmar que, dados os seus fins e meios propostos, a cooperação estruturante em saúde, promovida pelo Brasil, dedica-se à efetivação dessa segunda agenda.

Além disso, se o direito internacional busca responder a problemas que surgem dentro dos Estados, há de se entender o processo pelo qual um determinado problema, ou demanda, nas palavras de Clarissa Dri ${ }^{22}$, acaba por se tornar pauta para ação do direito internacional. Nessa seara, pode-se utilizar do processo elencado por Kingdon ${ }^{23}$, para pensar o processo de criação de políticas públicas em âmbito doméstico, para pensar também quais variáveis interagem na transformação da demanda doméstica em ação do direito internacional. Para o autor, três variáveis distintas interagem nesse processo: o problema, a solução, e a política — ou processo político. Nessa interação, os atores são responsáveis por perceber e interpretar um problema, e por pensar uma solução, que é a política pública, que deverá passar por processos políticos nas instâncias responsáveis por realizá-la.

Ainda, se o fim do direito internacional, assim como o da cooperação estruturante em saúde, é o âmbito doméstico, é necessário entender como ele penetra a membrana estatal e se torna efetivo nessa esfera. Para isso, pode-se utilizar o conceito de política pública de $\mathrm{Bucci}^{24}$, que entende política pública como "programas

22 DRI, Clarissa Franzoi. Demanda e oferta de bens públicos regionais: políticas públicas transnacionais na América do Sul? Revista de Iniciação Científica em Relações Internacionais, João Pessoa, v. 3, n. 6, p. 1-8, 2016.

23 KINGDON, John Wells. Juntando as coisas. In: SARAVIA, E. FERRAREZI, E. (org.). Políticas Públicas - Coletânea. Brasília: ENAP, 2006. p. 225-246. v. 1.

24 BUCCI, Maria Paula Dallari. Buscando um conceito de políticas públicas para a concretização dos direitos humanos. Cadernos Pólis 2: Direitos Humanos e Políticas Públicas, São Paulo, Instituto Pólis, v. 2, p. 5-16, 2001. 
de ação governamental voltados à concretização de direitos" 25 , para sugerir que não há concretização de direitos sem instituições governamentais fortes.

Nesse sentido, pode-se dizer que a cooperação internacional que se propõe estruturante possui duas dimensões. Na primeira, ela é o resultado da soma do problema, da solução e dos processos políticos. Onde o problema depende dos interesses dos atores em reconhecê-los, e a solução são as ideias dos atores para resolver um problema reconhecido, enquanto o processo político corresponde ao crivo das ideias por um novo grupo de interesses. O produto dessa soma toma a forma de atos internacionais - que apesar de dizerem muito sobre possibilidades, não são eficazes, se não quando passam a ser parte de uma nova soma.

Nesse novo cálculo, que representa a segunda dimensão, o produto da soma anterior precisa de instituições fortes. Ou seja, nela o ato internacional é fonte de instrumentos, para que as instituições do aparelho estatal construam políticas públicas locais. $\mathrm{Na}$ perspectiva de Bucci $^{26}$, essas duas dimensões seriam um caminho para a efetivação de um direito, "desde o seu nascimento, quando é previsto na norma, até a sua emancipação, quando é encartado em determinado programa de ação de um governo e passa a integrar medidas de execução" ${ }^{27}$.

A descrição das categorias, presentes nas duas dimensões, tem interesses específicos: Hall ${ }^{28}$ atenta para os ganhos possíveis, em termos de abrangência de análise quando se colocam em discussão as ideias, os interesses e as instituições na formação de políticas públicas. Assim, quando a variável problema é colocada em posição de dependência em relação aos interesses, e a

25 BUCCI, Maria Paula Dallari. Buscando um conceito de políticas públicas para a concretização dos direitos humanos. Cadernos Pólis 2: Direitos Humanos e Políticas Públicas, São Paulo, Instituto Pólis, v. 2, p. 5-16, 2001. p. 13.

26 BUCCI, Maria Paula Dallari. Buscando um conceito de políticas públicas para a concretização dos direitos humanos. Cadernos Pólis 2: Direitos Humanos e Políticas Públicas, São Paulo, Instituto Pólis, v. 2, p. 5-16, 2001.

27 BUCCI, Maria Paula Dallari. Buscando um conceito de políticas públicas para a concretização dos direitos humanos. Cadernos Pólis 2: Direitos Humanos e Políticas Públicas, São Paulo, Instituto Pólis, v. 2, p. 5-16, 2001. p. 12.

28 HALL, Peter Andrew. The role of interests, institutions, and ideas in the comparative political economy of industrialized nations. In: LICHBACK, M. ZUCKERMAN, A. (org.). Comparative politics: rationality, culture and structure. New York: Cambridge University Press, 1997. solução representa ideias - que interagem na fase dos processos políticos — , enquanto o ato internacional que é produto dessa interação — somente ganha eficácia quando associado às instituições, o que se busca é "permanecer atento à pluralidade das possíveis dimensões da análise e à diversidade de 'causas' possíveis no mundo do estudo da ação pública" ${ }^{29}$.

Importa também atentar para a localização dessas dimensões. Os processos elencados pela primeira dimensão passam necessariamente pelo nível internacional, pois os atos internacionais são firmados de maneira interestatal, ainda que os problemas advenham de demandas intraestatais. Enquanto os processos da segunda dimensão ocorrem, exclusivamente, no nível intraestatal. E isso importa porque, para Slaughter e Burke-White $^{30}$, o resultado advindo das mudanças na atuação do direito internacional na contemporaneidade, e portanto, nas fronteiras entre as esferas doméstica e internacional, que agora se confundem, cruzam e até conflitam, "será jogos de dois níveis cada vez mais elaborados, mas cada jogo permanecerá em seu próprio tabuleiro, não importando o quão complexos e densos sejam os elos entre eles" 31

Ainda,

o processo de internacionalização do direito pressupõe novos níveis de interação entre os diferentes atores nacionais e internacionais. De um lado, o direito internacional se forma a partir de novas formas de criação, implementação e controle de normas pelos Estados. De outro, a partir da intensificação de formas de relacionamento entre os atores transnacionais e subnacionais, públicos e privados. $^{32}$

Assim, se os níveis correspondem a "jogos" diferentes, com atores e interesses diferentes daqueles que se poderá notar no nível seguinte, faz sentido que o estu-

29 PALIER, Bruno; SUREL, Yves. Les Trois I et l'analyse de l'Etat em action. Revue française de science politique, Paris, v. 55, n.1, p.732, 2005. p. 8.

30 SLAUGHTER, Anne-Marie; BURKE-WHITE, William. The Future of International Law is Domestic (or, The European Way of Law). Harvard International Law Journal, Cambridge, v. 47, n. 2, jun. 2006.

31 SLAUGHTER, Anne-Marie; BURKE-WHITE, William. The Future of International Law is Domestic (or, The European Way of Law). Harvard International Law Journal, Cambridge, v. 47, n. 2, jun. 2006. p. 350.

32 VARELLA, Marcelo Dias. Internacionalização do Direito: superação do paradigma estatal e a insuficiência de estruturas de diálogos. Revista de Direito Internacional, Brasília, v. 9, n. 4, p. 1-5, 2012. p. 1. 
do de cada nível corresponda a empreitadas científicas diferentes. Dessa forma, em que pese se reconhece a necessidade de verificar a construção material de políticas públicas no âmbito dos Estados que compõem os esquemas de cooperação estudados - e que este constitui interesse de pesquisa futuro - o presente trabalho se ocupa da primeira dimensão da cooperação internacional estruturante. Tendo por objeto o produto dessa primeira dimensão, o ato internacional. Assim, busca-se primeiro verificar quais regimes temáticos em matéria de saúde os atos firmados pelo Brasil são capazes de formar, e segundo, com base na quantificação desses regimes, identificar em qual agenda internacional da saúde se situa a ação brasileira. E, por último, busca-se compreender em que grau os termos desses atos internacionais correspondem às categorias de cooperação estruturante, evidenciando quais são as possibilidades de efetivação estruturante presente no acervo documental do Brasil com os demais países da América do Sul.

Assim, ao analisar o produto da primeira soma, o presente estudo se restringe à análise dos interesses dos atores e ideias envoltos no nascimento de um direito, que correspondem ao reconhecimento do "problema" e ao desenvolvimento da "solução" de Kingdon ${ }^{33}$, deixando a categoria dos processos políticos apenas para estudos com outros métodos de procedimento. Isto porque, este estudo caracteriza-se como um levantamento, que segundo $\mathrm{YIN}^{34}$, fornece indicações da predominância de fenômenos, enquanto é objetivo de estudos de caso fornecer interpretações sobre processos causais.

\section{Quais problemas sobreviveram ao processo político: das dimensões quantitativas às dimensões geográficas e espaços institucionais}

Esta seção é dedicada à compreensão sobre os interesses, ou sobre quais problemas foram mais interessantes aos atores, a ponto de produzirem ideias, ou soluções capazes de sobreviver ao processo político e se traduzirem nos termos que formam o conteúdo

\footnotetext{
33 KINGDON, John Wells. Juntando as coisas. In: SARAVIA, E. FERrAREZI, E. (org.). Políticas Públicas - Coletânea. Brasília: ENAP, 2006. p. 225-246. v. 1.

34 YIN, Robert. Estudo de caso: planejamento e métodos. 2. ed. Porto Alegre: Bookman, 2001
}

dos atos internacionais, estudado na seção seguinte. É de sua responsabilidade expor quais são as dimensões quantitativas e geográficas dos regimes formados pelos atos internacionais firmados pelo governo brasileiro com os governos dos demais Estados da América do Sul, em matéria de saúde e vigentes até a data do último levantamento em cada mecanismo de busca. Identificar quais são os regimes significa perguntar "o que esses atos internacionais positivam?", enquanto identificar as dimensões quantitativas, geográficas, e os espaços institucionais onde eles nasceram significa perguntar "quem está preocupado em positivar isso?".

Cabe informar que o banco de dados que embasará as lições seguintes foi construído com base em critérios específicos, e, por isso, é constituído de limites, em certa medida, bem definidos. Nesse sentido é relevante esclarecer como são construídas as fronteiras do campo onde se deu o trabalho, ou na metáfora de Rebecca Lemos Igreja ${ }^{35}$, da "aldeia". Em primeiro lugar, o presente trabalho se dispõe ao estudo dos atos internacionais firmados pelo governo brasileiro com os governos dos demais países da América do Sul, que positivam ações concretas em direção ao desenvolvimento em termos de saúde, ou seja, estão excluídos atos internacionais como declarações conjuntas que contenham, apenas, informações superficiais sobre saúde, por exemplo, congratulações ou objetivos muito abrangentes e abstratos. Em segundo lugar, esses atos positivam a saúde humana e pública, bem como o fortalecimento de instituições e ações de capacitação que possuem enfoque principal sobre esta, de maneira que atos referentes à sanidade animal e vegetal também estão excluídos, ainda que se reconheça que estes possuam certo grau de influência sobre a mesma.

Ainda, outra informação relevante refere-se ao fato de que se desenha um contexto em que diversos atos não necessitaram de ratificação, por não implicarem qualquer compromisso de transferência de recursos financeiros entre as Partes ou qualquer outra atividade gravosa aos respectivos patrimônios nacionais ${ }^{36}$. Ou-

\footnotetext{
IGREJA, Rebecca Lemos. O Direito como objeto de estudo empírico: o uso de métodos qualitativos no âmbito da pesquisa empírica em Direito. In: Machado, Maíra Rocha (org.). Pesquisar empiricamente o direito. São Paulo: Rede de Estudos Empíricos em Direito, 2017. p. 11-37.

36 Como elenca o artigo III, inciso 3, do Ajuste complementar ao Acordo de Cooperação Técnica entre o Governo da República Federativa do Brasil e o Governo da República Argentina para implementação do projeto "Fortalecimento do programa de controle da
} 
tros, ainda, contêm artigos que diminuiriam a força jurídica desses instrumentos normativos, pois segundo seus próprios termos, não geram obrigações ou responsabilidades jurídicas internacionais para nenhum Governo ${ }^{37}$. Enquanto alguns atos multilaterais, notadamente mercossulinos, contêm cláusulas em que consta a sua não necessidade de incorporação ao ordenamento jurídico dos Estados Partes, por regulamentar aspectos da organização ou do funcionamento do MERCOSUL ${ }^{38}$, ainda que de várias maneiras eles não se restrinjam a essa função.

Nenhuma das condições acima citadas implicou a exclusão de atos internacionais da aldeia, justamente pelas ideias que a desenharam, pois, se o fim da cooperação estruturante é penetrar na membrana estatal produzindo abordagens autônomas de valores compartilhados, então, pode-se afirmar que as ratificações, por exemplo, "não são o 'momento mágico' de aceitação das normas de direitos humanos. Pelo contrário, a ratificação é um ponto no processo mais amplo de incorporação" 39. Aqui "a ratificação pode representar a iniciação, a culminação ou a reconfiguração de uma luta política doméstica" ${ }^{40}$. Ou seja, mesmo normas que não necessitam de ratificação têm espaço na aldeia em que se poderá ou não encontrar cooperação estruturante, isto porque, mesmo atos internacionais sem força jurídica vinculante, ao receberem publicidade internacional, têm repercussão política, e contribuem para o poder de compelir do direito internacional. ${ }^{41}$

dengue", bem como muitos outros atos internacionais.

37 Como no caso da cláusula quarta do Memorando de Entendimento entre o Ministério da Saúde da República Federativa do Brasil e o Ministério da Saúde Pública e Assistência Social da República do Peru na área da Saúde, e de outros atos internacionais.

38 Como no caso do artigo $3^{\circ}$ da Decisão no $16 / 12$, do Conselho do Mercado Comum, referente a Rede de pontos focais de saúde para a prevenção e o combate à falsificação de medicamentos e produtos médicos no Mercosul. Além de outros atos internacionais do Mercosul.

39 GOODMAN, Ryan.; JINKS, Derek. Measuring the Effects of Human Rights Treaties. European Journal of International Law, v. 14, n. 1, p. 171-183, 2003. p. 173.

40 GOODMAN, Ryan.; JINKS, Derek. Measuring the Effects of Human Rights Treaties. European Journal of International Law, v. 14, n. 1, p. 171-183, 2003. p. 174.

${ }_{41}$ TORRONTEGUY, Marco Aurélio Antas. O direito humano à saúde no direito internacional: efetivação por meio da cooperação sanitária. 2010. Tese (doutorado) - Faculdade de Direito, Universidade de São Paulo, São Paulo, 2010.

\subsection{0 acervo bilateral}

Sobre os atos bilaterais em saúde, a coleta de dados e documentos se deu no site da Divisão de Atos Internacionais "Concórdia", do Ministério das Relações Exteriores do Brasil (MRE), e no site do Ministério da Saúde do Brasil (MS), mais especificamente na sua Assessoria Internacional (AISA). No primeiro, objetivando a maior completude possível, a busca se deu sem o uso de marcadores temáticos, apenas de vigência, país a país, todos os 11 demais componentes independentes da América do Sul, de maneira que foram identificados 1681 atos em vigor, e destes, 119 são em saúde, seja por completo - portanto estritos em saúde — ou em alguns artigos - portanto atos internacionais de caráter incidental em saúde.

Foram as buscas iniciais no MRE somadas à leitura da obra de Torronteguy ${ }^{42}$, os responsáveis por demonstrar que atos mais abrangentes, ou de temáticas em sua maioria sociais, poderiam conter artigos referentes à saúde. Para organizar esses dados e compreender de fato a maior quantia possível de ações concretas em saúde no âmbito da América do Sul, foram desenvolvidos os conceitos de ato internacional "estrito" e "incidental" em saúde. Estrito é todo ato cujo objetivo maior é regular um tema de saúde, enquanto incidental é aquele ato que positiva ação concreta na temática, ou que impacta, diretamente, a temática de saúde em algum de seus artigos, apesar de seu objetivo maior não ser essa temática.

Isso não significa, cabe ressaltar, que os atos incidentais em saúde, analisados aqui, abordam os determinantes sociais em saúde, que foram estudados de forma profícua na obra de Torronteguy ${ }^{43}$ — na qual seu objeto são os atos em saúde firmados pelo governo brasileiro com os governos dos Países Africanos de Língua Oficial Portuguesa - , significa, apenas, que ações em saúde estão contidas em alguns artigos de alguns atos que se referem, por exemplo, ao uso pacífico da energia nuclear ${ }^{44}$.

42 TORRONTEGUY, Marco Aurélio Antas. O direito humano à
saúde no direito internacional: efetivação por meio da cooperação
sanitária. 2010. Tese (Doutorado) - Faculdade de Direito, Universi-
dade de São Paulo, São Paulo, 2010.
43 TORRONTEGUY, Marco Aurélio Antas. O direito humano à
saúde no direito internacional: efetivação por meio da cooperação
sanitária. 2010. Tese (Doutorado) - Faculdade de Direito, Universi-
dade de São Paulo, São Paulo, 2010.
44 Como por exemplo no artigo $1^{\circ}$, inciso iii, do Protocolo adi- 
Além disso, os 69 ajustes complementares que constam entre esses 119 atos advêm de 12 acordos-quadro distintos, que não são considerados durante a classificação de regimes temáticos ou de categorias de cooperação estruturante. Isto porque 11 desses atos versam sobre a abertura daquilo que seriam programas de cooperação técnica, científica, ou tecnológica, e, apenas, um deles, de cooperação técnica com a Argentina, dispõe de áreas temáticas prioritárias, e entre elas a saúde. Os outros 10 acordos quadro, mais um com a Argentina, e um com cada um dos demais países independentes da América do Sul, com exceção do Chile, dispõem das possíveis formas de cooperação, mas não de áreas prioritárias, portanto, eles nem mesmo são incidentais em saúde, segundo a classificação proposta por esse trabalho.

Outro fator que torna os acordos-quadro menos importantes para fins de levantamento é que, de maneira geral, as condições propostas por eles, e que poderiam ser objeto de quantificação, se repetem ou são especificadas nos ajustes complementares, e já serão, então, abrangidas neste trabalho. Completando esses 12, e de ordem distinta dos demais, é o Acordo entre o Governo da República Federativa do Brasil e o Governo da República Oriental do Uruguai para permissão de residência, estudo e trabalho a nacionais fronteiriços brasileiros e uruguaios, de onde advém o ajuste complementar entre esses mesmos governos para a prestação de serviços de saúde.

$\mathrm{Na}$ prática, os acordos-quadro se apresentam como aquilo que, metaforicamente, seria o "manual", no qual consta como devem ser escritos ajustes complementares, e estes, ao menos os aqui abordados, acrescem suas cláusulas, mas não as deixam de repetir. E, apesar de os acordos-quadro não receberem maior tratamento nessa empreitada científica, eles serão importantes durante uma possível próxima fase de estudos de caso sobre cada regime temático específico. Aqui, ainda, eles fornecem uma lição, que importa às preocupações com a prática brasileira e sul-americana da cooperação internacional, de maneira geral. Pois, apesar da cooperação horizontal, ou Sul-Sul, ser em sua origem referida pela Organização das Nações Unidas, como Cooperação Técnica entre Países em Desenvolvimento (CTPD), 5

cional ao Acordo de cooperação para o desenvolvimento de energia nuclear para fins pacíficos em matéria de reatores, combustíveis nucleares, abastecimento de radioisótopos e radiofármacos, e de gestão de resíduos radiativos, firmado entre o Brasil e a Argentina. desses 11 acordos-quadro que versam sobre abertura de programas de cooperação técnica, científica ou tecnológica, versam sobre outra modalidade que não a técnica, demonstrando nuances de maior autonomia e reconhecimento entre os países do Sul.

No caso do segundo site, do Ministério da Saúde, as listas de atos em saúde algumas vezes informam um link para o documento, e outras vezes um link para a página do ato internacional referido na plataforma Concórdia. Dessa forma, para lidar com as divergências entre os dados, conformou-se a máxima de que todos os atos internacionais colhidos deveriam estar em vigor segundo o MRE até o dia 06 de junho de 2018, último acesso em ambos os sites. Nesse sentido, todo ato em saúde salvo as delimitações temáticas e de ação — que consta vigente no banco de dados do MRE, faz parte do banco de dados do presente trabalho, independente do seu status pelo MS.

Assim, no site do MS haviam 98 atos internacionais referentes à região da América do Sul, e 10 deles fazem parte do banco de dados final do presente trabalho. Desses 10 atos, que apenas constam no MS, e que lá estão vigentes, assim como no MRE, 9 são denominados como interinstitucional, firmados diretamente entre Ministérios ou Ministros da Saúde, e não por Ministérios ou Ministros de Relações Exteriores, ou ainda, representantes desse Ministério ou do Governo de maneira geral, e 1 envolve "diretamente" o Governo, o que, em algum grau, poderia explicar porque são exclusivos desse site.

Por fim, o acervo de atos bilaterais em saúde deste trabalho é composto por 129 atos internacionais estritos e incidentais em saúde, excluídos os acordos-quadro, pelos motivos citados anteriormente. E, com base nesse acervo, consegue-se averiguar a existência de, pelo menos, 9 regimes temáticos densos, ou seja, com 3 ou mais atos internacionais. Agrupados de acordo com a temática principal, ou a principal preocupação, descrita normalmente nos seus títulos ou primeiros artigos, com exceção do regime Geral em matéria de saúde, que corresponde àqueles acordos cujas disposições impactam de maneira geral a temática de saúde, ou regulam mais de duas ações concretas em saúde, geralmente em vários artigos distribuídos pelo corpo do tratado.

Os 9 regimes temáticos são: geral em matéria de saúde (23 atos), Fortalecimento institucional (18 atos), Saúde fronteiriça (13 atos), Farmacodependência (13 atos), 
Bancos de leite humano (11 atos), DST/HIV/Aids (10 atos), Previdência social ( 9 atos), Medicamentos e afins (6 atos), Saúde indígena ( 3 atos). E, além deles, há uma categoria, Outros (23 atos), que reúne regimes com menor densidade de atos internacionais, agrupados pelos mesmos critérios dos regimes anteriores - com exceção do Geral em matéria de saúde —, são eles: Doença de Chagas (2 atos), Leishmaniose (2 atos), Saúde em meios tropicais (2 atos), Biotecnologia (2 atos), Saúde e segurança no trabalho (2 atos), Medicina nuclear (2 atos), Surtos epidêmicos e pandêmicos (2 atos), Dengue (1 ato), Cólera (1 ato), Hidatidose (1 ato), Complexo Industrial da Saúde (1 ato), Transplante de órgãos e tecidos (1 ato), Vigilância e controle de resíduos e contaminantes em alimentos (1 ato), Pesquisa em saúde (1 ato), Soro antiofídico (1 ato), Tratamento médico de pacientes guianenses em hospitais brasileiros (1 ato). Todos esses reunidos no gráfico abaixo, seguido do gráfico que demonstra as dimensões geográficas de cada um.

GRÁFICO 1 - Regimes temáticos formados pelos atos bilaterais em saúde firmados pelo governo brasileiro com os demais governos da América do Sul: a dimensão quantitativa (129 atos internacionais)

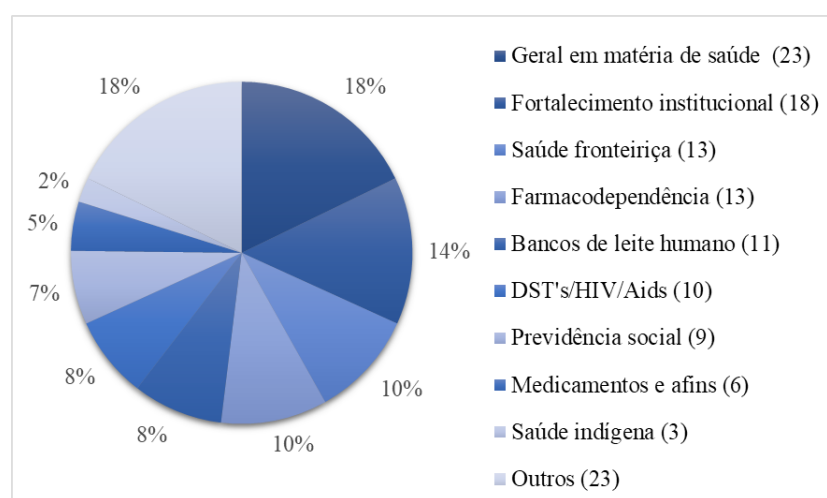

Fonte: autores

GRÁFICO 2 - As dimensões geográficas dos regimes temáticos bilaterais em saúde Brasil-América do Sul

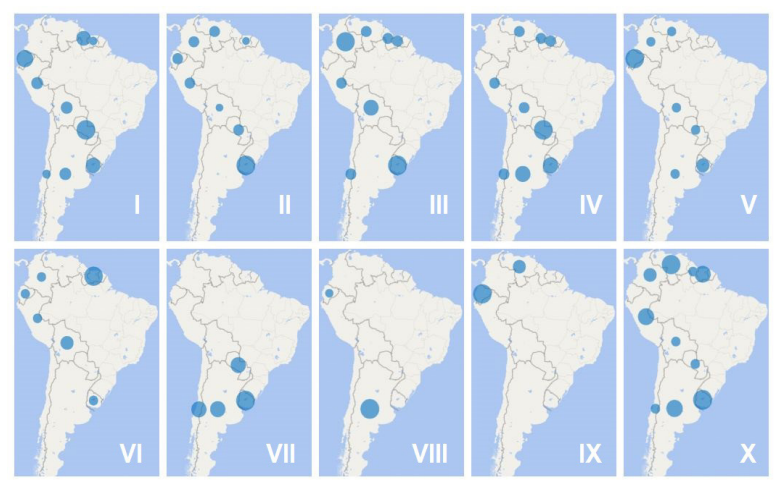

Fonte: autores
A disposição dos regimes temáticos, no gráfico 2, corresponde à mesma disposição do gráfico 1: Geral em matéria de (I), Fortalecimento institucional (II), Bancos de leite humano (III), Medicamentos e afins (IV), DST/ HIV/Aids (V), Saúde fronteiriça (VI), Farmacodependência (VII), Previdência social (VIII), Saúde indígena (IX), e Outros (X).

A quantificação do acervo de atos bilaterais coletado, apresentada no gráfico 1, demonstra a existência de, pelo menos, 9 regimes temáticos densos dedicados à efetivação do direito humano à saúde, agrupados durante a análise inicial dos documentos, bem como de um regime Outros, marcado por 16 temáticas diferentes, em menores dimensões. Entre os regimes temáticos densos, está o regime de Fortalecimento institucional, o segundo maior, e que parece ser a representação fidedigna da cooperação estruturante em saúde, envolvendo instituições estruturantes, com o objetivo de fortalecê-las. E, em termos de dimensões geográficas, apresentadas no gráfico 2, o parceiro com o qual esse regime temático ganha maior densidade, 6 atos, é o Uruguai, seguido de Colômbia, Equador, Paraguai, Peru, e Venezuela, com 2 atos cada, e de Bolívia e do Suriname, com 1 ato cada. Nota-se algum grau de concentração da prática, e a falta da Argentina, a segunda maior economia da região, nesse regime. Informações que, talvez, caibam às lições futuras.

\subsection{0 acervo multilateral}

Sobre os atos multilaterais, foram considerados os atos criados no âmbito das duas organizações sul-americanas que incluem o Brasil e apresentam algum tipo de interesse em positivar questões de saúde: o Mercosul e a Unasul. Mas é importante salientar que toda a construção teórica e revisão bibliográfica teve como objeto a cooperação estruturante em saúde, enquanto objeto de política externa ou ferramenta dos países em desenvolvimento para a efetivação de direitos humanos. E que, nesse sentido, quando a pesquisa se volta para o acervo das instituições sul-americanas para buscar atos internacionais multilaterais, ela tem uma delimitação específica: apesar dessas instituições serem notadamente voltadas à integração, são buscados atos de cooperação formados no âmbito dessas instituições, e para tanto elas são vistas como fóruns, onde os temas são debatidos e acordos são firmados. 
Ou seja, foram considerados, apenas, aqueles atos que envolviam ação direta das instituições nacionais, e não da instituição internacional propriamente dita. A exemplo estão os mecanismos de articulação, os mecanismos de notificação obrigatória sobre doenças, o intercâmbio de informação e as redes, firmados por atos internacionais das instituições em questão, mas que são objeto de instituições nacionais. Esses exemplos não produzem resultados integrados, nem são realizados por órgãos internos à instituição internacional com os fundos elencados pelos Governos. Ou seja, o ato é firmado na ou pela instituição, mas o poder de realizá-lo não depende (exclusivamente) dela. Nessa perspectiva a cooperação internacional é vista como um processo que conserva, e até mesmo aumenta, as funções referentes ao Estado nacional, e não a transferência dessas para o âmbito regional, e a "consequente diminuição da margem de ação nacional autônoma" 45 , como se propõe a integração.

Além de enfoque sobre a saúde humana e pública, e do aspecto de cooperação, esse acervo conta com uma nova delimitação. Ocorre que boa parte da normativa em saúde do Mercosul se trata de atos internacionais que têm por objeto a harmonização de normas sanitárias visando à liberalização comercial, que também é um processo que demanda a ação de instituições nacionais, e que não resulta em fins integrados. No entanto, esses atos não foram incluídos. Isto porque a quantidade de atos internacionais nessa temática não só é grande, como demanda um trabalho sistemático, pois eles parecem ser substituídos com maior frequência, e se referem a variados tipos de produtos, como cosméticos e produtos alimentícios.

Os produtos aos quais se referem esses atos podem incidir sobre a saúde humana, mas povoariam esse acervo com grande número de atos incidentais em saúde, em temáticas muito periféricas àquela que é o foco dessa empreitada, que alterariam as respostas para as perguntas feitas inicialmente. Além disso, documentos ligados, principalmente, a questões de comércio foram excluídos anteriormente, em trabalho que também visava compreender a normativa em saúde destas instituições ${ }^{46}$.

\footnotetext{
45 VIGEVANI, Tullo; RAMANZINI JUNIOR, Haroldo. Autonomia, integração regional e Política Externa Brasileira: Mercosul e Unasul. Dados - Revista de Ciências Sociais, Rio de Janeiro, v. 57, n. 2, p. 517-552, abr./jun. 2014. p. 519.

46 PITTAS, Tiago Mocellin. O estado da cooperação em saúde:
}

Tiago Pittas ${ }^{47}$ conduziu um estudo empírico que englobava toda a normativa em saúde das duas instituições sul-americanas aqui estudadas, e, portanto, também abrangeu documentos que produzem resultados integrados. Segundo o autor, no caso do Mercosul, "em relação aos documentos que possuem foco principalmente apontado para a preocupação com o tema da saúde pública, sem considerar aqueles essencialmente ligados a padrões de comércio, o número é de aproximadamente 80 até 2013 ” 48 . Enquanto "um diagnóstico inicial de documentos gerais, declarações, acordos, comunicados e protocolos realizados no âmbito da Unasul envolvendo a temática da saúde, até o ano de 2013, aponta para cerca de 92 documentos elaborados" $"$.

No caso da busca no site brasileiro do Mercosul, também sem marcadores temáticos, foram excluídas Diretrizes do Conselho de Comércio do Mercosul (CCM), por tratarem, essencialmente, de temas de comércio, e Recomendações do Conselho do Mercado Comum (CMC), dado que elas não apresentaram ações concretas em saúde. $\mathrm{Na}$ aba "Decisões", haviam 1.035 atos, entre eles: Decisões e Recomendações do CMC, além de Protocolos, Memorandos de Entendimento, e Acordos, firmados de 1991 a 2017, destes, 4 Decisões referem-se à cooperação em saúde e estão vigentes, e, portanto, fazem parte do banco de dados total aqui analisado. Em relação as 1.767 Resoluções do Grupo Mercado Comum (GMC), firmadas entre 1991 e 22 de junho de 2018 — data do último acesso —, 5 referem-se à cooperação em saúde e estão vigentes. De forma que 9 atos dos 2802 atos internacionais do Mercosul acessados fazem parte do banco de dados aqui estudado.

No caso da segunda instituição, o site oficial da Unasul possui organização confusa e de difícil acesso, sem delimitações de qualquer tipo, o banco de dados é constituído de uma lista de várias páginas, contendo links diretos para 1.118 documentos, em sua maioria es-

Brasil, Mercosul e Unasul. Revista de Iniciação Científica em Relações Internacionais, João Pessoa, v. 3, n. 6, p. 138-162, 2016.

47 PITTAS, Tiago Mocellin. O estado da cooperação em saúde: Brasil, Mercosul e Unasul. Revista de Iniciação Científica em Relações Internacionais, João Pessoa, v. 3, n. 6, p. 138-162, 2016. 48 PITTAS, Tiago Mocellin. O estado da cooperação em saúde: Brasil, Mercosul e Unasul. Revista de Iniciação Científica em Relações Internacionais, João Pessoa, v. 3, n. 6, p. 138-162, 2016. p. 152.

49 PITTAS, Tiago Mocellin. O estado da cooperação em saúde: Brasil, Mercosul e Unasul. Revista de Iniciação Científica em Relações Internacionais, João Pessoa, v. 3, n. 6, p. 138-162, 2016. p. 154. 
caneados, e com títulos não padronizados. Nesse caso optou-se por preencher o filtro "Contenido (Palaba o frase)", disponível em "Búsqueda de documentos", com a palavra "salud", surgindo, então, uma nova lista com 277 registros, entre atas de reuniões, resoluções de diferentes Conselhos e decisões do Conselho de Chefas e Chefes de Estado e Governo. A respeito desses documentos, 7 referem-se à cooperação em saúde: 3 são Resoluções do Conselho de Ministras e Ministros de Relações Exteriores, 3 são Resoluções do Conselho de Saúde Sul-Americano, e 1 é Decisão do Conselho de Chefas e Chefes de Estado e Governo. A vigência deles não consta em nenhum lugar no site. A exceção aberta a esses atos internacionais, dada a falta de informação sobre a vigência dos mesmos, se deu em função da Unasul ser reconhecida como responsável por outras representações fidedignas do conceito de cooperação estruturante em saúde ${ }^{50}$, sobre as quais a análise é relevante no contexto do presente estudo.

Desse segundo acervo, formado por 16 atos internacionais, pode-se averiguar a existência de, pelo menos, 2 regimes temáticos densos: Redes de cooperação em saúde (8 atos) e Medicamentos e afins (4 atos). Além da categoria Outros (4), que reúne os regimes temáticos de cooperação com menor densidade em atos internacionais nas instituições sul-americanas das quais o Brasil faz parte: Mecanismo de Articulação para a Atenção a Mulheres em situação de Tráfico Internacional (1 ato), Síndrome Respiratória Aguda Grave (1 ato), Assistência humanitária e saúde (1 ato), Plataforma de intercâmbio de experiências e assistência técnica para prevenção e controle de câncer de colo de útero na América do Sul (1 ato). Os gráficos a seguir reúnem essas informações em termos quantitativos e as localizam em termos de espaços institucionais.

GRÁFICO 3 - Regimes temáticos formados pelos atos multilaterais em saúde firmados pelas instituições sul-americanas das quais o Brasil faz parte

50 BUSS, Paulo Marchiori.; FERREIRA, José Roberto. Cooperação e integração regional em saúde na América do Sul: a contribuição da Unasul Saúde. Revista Ciência \& Saúde Coletiva, Rio de Janeiro, v. 16, n. 6, p. 2699-2711, jun. 2011.

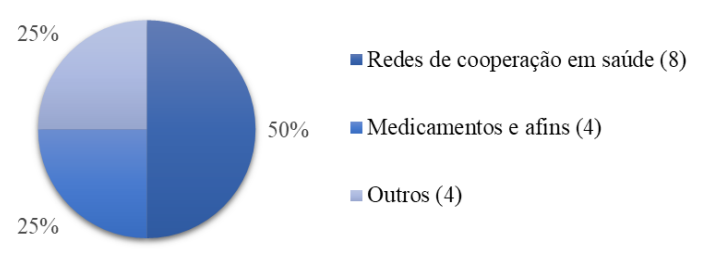

Fonte: autores

GRÁFICO 4 - Os espaços institucionais onde se formam os regimes temáticos multilaterais em saúde Brasil-América do Sul

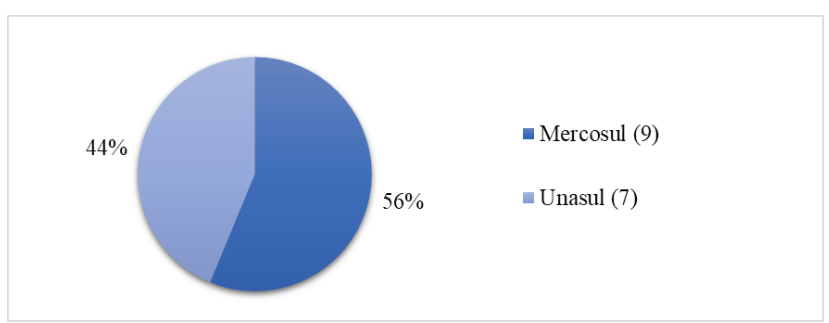

Fonte: autores

A quantificação do acervo de atos multilaterais coletado, apresentada no gráfico 3, demonstra a existência de 2 regimes temáticos densos, e uma categoria "Outros". O maior deles, intitulado "Redes de cooperação em saúde", trata da construção de redes de cooperação entre instituições de saúde, estruturantes e nacionais, para fins específicos. Essas redes são, para Ferreira e Fonseca $^{51}$, estratégias de potencialização da cooperação estruturante em saúde. As da Unasul já possuem certo reconhecimento ${ }^{52}$, mas a novidade é que há também duas Redes criadas no âmbito do Mercosul — positivadas em 3 atos internacionais - uma de institutos de pesquisa em biomedicina, e uma de pontos focais de saúde para a prevenção e o combate à falsificação de medicamentos e produtos médicos. Esse regime, assim como o regime temático de Fortalecimento institucional no acervo bilateral, se apresenta, ao menos de maneira documental, como uma demonstração fidedigna da abordagem da cooperação estruturante em saúde.

Em termos de espaços institucionais, o regime de Redes de cooperação em saúde se mostra mais denso na Unasul, com 5 redes, sendo elas, de formação de pessoal para os sistemas de saúde, de oficinas de relações

51 FERREIRA, José Roberto; FONSECA, Luiz Eduardo. Cooperação estruturante, a experiência da Fiocruz. Revista Ciência \& Saúde Coletiva, v. 22, n. 7, p. 2129-2133, jul. 2017.

52 BUSS, Paulo Marchiori.; FERREIRA, José Roberto. Cooperação e integração regional em saúde na América do Sul: a contribuição da Unasul Saúde. Revista Ciência \& Saúde Coletiva, Rio de Janeiro, v. 16, n. 6, p. 2699-2711, jun. 2011. 
internacionais e cooperação internacional em saúde, de prevenção da dengue, de escolas de saúde pública, e de investigação para o desenvolvimento tecnológico, transferências de tecnologia, controle e vigilância epidemiológica de enfermidades transmitidas por vetores. Além disso, os atos firmados no âmbito da Unasul determinam instituições estruturantes específicas e ligações entre as diversas redes, um aspecto não tão bem desenvolvido no Mercosul.

\section{0 desenho das soluções: as possibilidades de efetivação estruturante nos regimes temáticos}

Esta seção tem a função de analisar o conteúdo dos atos internacionais que formam o banco de dados final, com 145 atos internacionais, a fim de compreender quais ideias sobreviveram aos processos políticos e transformaram-se em soluções para os problemas pelos quais os atores demonstraram interesses, e que constituem os regimes temáticos acima apresentados. Essa análise representa a seguinte questão: "como se pretende efetivar o que foi positivado?”, e é ela a responsável por esclarecer as possibilidades de efetivação estruturante presentes ou não nos regimes temáticos.

A presença de instituições estruturantes representa um elemento de alta relevância, assim como a ideia do fortalecimento dessas instituições, para situar algum regime no âmbito da cooperação estruturante em saúde, e são, portanto, categorias analisadas. Mas, para identificar, de maneira mais ampla, as possibilidades de efetivação estruturante, ou seja, averiguar se a prática brasileira da cooperação estruturante em saúde conseguiu transbordar para regimes que não realizem especificamente a sua agenda, é preciso um outro grupo mais abrangente de categorias e a sua quantificação. Essas categorias foram escolhidas tendo por base a obra de Torronteguy ${ }^{53}$, comparada às ideias sobre cooperação estruturante em saúde presentes nas obras de Almeida et al. ${ }^{54}$, Buss e

\footnotetext{
53 TORRONTEGUY, Marco Aurélio Antas. O direito humano à saúde no direito internacional: efetivação por meio da cooperação sanitária. 2010. 355 p. Tese (Doutorado) - Faculdade de Direito, universidade de São Paulo, São Paulo, 2010.

54 ALMEIDA, Celia; CAMPOS, Rodrigo Pires de; BUSS, Paulo; FERREIRA, José Roberto; FONSECA, Luiz Eduardo. A concepção brasileira de cooperação Sul-Sul estruturante em saúde". Revista Eletrônica de Comunicação, Informação e Inovação em Saúde, Rio
}

Fonseca $^{55}$, e Ferreira e Fonseca ${ }^{56}$.

Visando compreender os níveis de horizontalidade e democratização da cooperação internacional, que, segundo ele, "são dois movimentos necessários para que a cooperação seja uma efetiva garantia do direito humano à saúde" ${ }^{\prime 57}$, Torronteguy ${ }^{58}$ selecionou as seguintes categorias para analisar os atos internacionais firmados pelo Brasil com os Países Africanos de Língua Oficial Portuguesa, em matéria de saúde: "informação sobre vigência, objetivos da cooperação, horizontalidade da relação bilateral, forma de avaliação das atividades, possibilidade de triangulação ou obtenção de financiamento junto a outros atores" 59 .

Ainda, as conclusões empíricas do autor somam a questão da participação da sociedade civil organizada, enquanto uma tendência na prática brasileira, importante à formatação de uma cooperação internacional mais democrática; enquanto a sustentabilidade é vista como um desafio para um modelo de cooperação Sul-Sul que abranja os valores da horizontalidade e de maior democracia. Para ele,

sustentabilidade, no contexto da cooperação
internacional, pode ser lida como temporariedade,
a fim de que o Estado recebedor da ajuda, com o
tempo, prescinda da ajuda estrangeira e tenha, nas
suas próprias instituições, condições de desenvolver
suas capacidades nacionais ${ }^{60}$.

Como elementos capazes de indicar horizontalidade o autor reconheceu:

de Janeiro, v. 4, p. 25-35, mar. 2010

55 BUSS, Paulo Marchiori; FONSECA, Luiz Eduardo. Diplomacia e cooperação em saúde: Uma perspectiva da Fiocruz. In: ALMINO, J; LIMA, S. E. M. (org.). 30 anos da ABC: visões da cooperação técnica internacional brasileira. Brasília: FUNAG, 2017.

56 FERREIRA, José Roberto; FONSECA, Luiz Eduardo. Cooperação estruturante, a experiência da Fiocruz. Revista Ciência \& Saúde Coletiva, v. 22, n. 7, p. 2129-2133, jul. 2017.

57 TORRONTEGUY, Marco Aurélio Antas. O direito humano à saúde no direito internacional: efetivação por meio da cooperação sanitária. 2010. 355 p. Tese (Doutorado) - Faculdade de Direito, Universidade de São Paulo, São Paulo, 2010. p. 247.

58 TORRONTEGUY, Marco Aurélio Antas. O direito humano à saúde no direito internacional: efetivação por meio da cooperação sanitária. 2010. Tese (Doutorado) - Faculdade de Direito, Universidade de São Paulo, São Paulo, 2010.

59 TORRONTEGUY, Marco Aurélio Antas. O direito humano à saúde no direito internacional: efetivação por meio da cooperação sanitária. 2010. 355 p. Tese (Doutorado) - Faculdade de Direito, Universidade de São Paulo, São Paulo, 2010. p. 178.

60 TORRONTEGUY, Marco Aurélio Antas. O direito humano à saúde no direito internacional: efetivação por meio da cooperação sanitária. 2010. 355 p. Tese (Doutorado) - Faculdade de Direito, Universidade de São Paulo, São Paulo, 2010. p. 252. 
coordenação conjunta dos programas e projetos de cooperação, necessidade de consenso para tornar públicos documentos da cooperação, ausência de condicionalidades, não verificação de seletividade, inexistência de endividamento, estabelecimento de mecanismos de consultas políticas ${ }^{61}$.

A apropriação das categorias selecionadas por Torronteguy ${ }^{62}$ para analisar o acervo normativo em saúde na América do Sul consiste não apenas nas semelhanças entre os objetivos das empreitadas, mas também no fato de que essas categorias foram englobadas pela abordagem da cooperação estruturante em saúde desde a sua primeira definição ${ }^{63}$ até as considerações atuais sobre ela. Pois, se ela busca promover o diálogo entre os atores, ampliar as relações horizontais ${ }^{64}$, e promover um caminho possível para a equidade nos países em desenvolvimento ${ }^{65}$, então ela almeja horizontalidade e aumento da democracia. Da mesma forma, se o fim da cooperação estruturante em saúde é possibilitar que esses atores sejam suficientemente fortes para formular autonomamente uma agenda para o desenvolvimento em saúde ${ }^{66}$, então, ela também está interessada em promover a sustentabilidade.

Aqui as categorias de Torronteguy ${ }^{67}$ foram agrupadas da seguinte forma: para refletir sobre a horizontalidade foram elencados cinco indicadores, o primeiro,

${ }_{61}$ TORRONTEGUY, Marco Aurélio Antas. O direito humano à saúde no direito internacional: efetivação por meio da cooperação sanitária. 2010. 355 p. Tese (Doutorado) - Faculdade de Direito, Universidade de São Paulo, São Paulo, 2010. p. 253.

62 TORRONTEGUY, Marco Aurélio Antas. O direito humano à saúde no direito internacional: efetivação por meio da cooperação sanitária. 2010. 355 p. Tese (Doutorado) - Faculdade de Direito, Universidade de São Paulo, São Paulo, 2010.

63 ALMEIDA, Celia; CAMPOS, Rodrigo Pires de; BUSS, Paulo; FERREIRA, José Roberto; FONSECA, Luiz Eduardo. A concepção brasileira de cooperação Sul-Sul estruturante em saúde". Revista Eletrônica de Comunicação, Informação e Inovação em Saúde, Rio de Janeiro, v. 4, p. 25-35, mar. 2010

${ }_{64}$ BUSS, Paulo Marchiori; FONSECA, Luiz Eduardo. Diplomacia e cooperação em saúde: uma perspectiva da Fiocruz. In: ALMINO, J; LIMA, S. E. M. (org.). 30 anos da ABC: visões da cooperação técnica internacional brasileira. Brasília: FUNAG, 2017.

${ }_{65}$ FERREIRA, José Roberto; FONSECA, Luiz Eduardo. Cooperação estruturante, a experiência da Fiocruz. Revista Ciência \& Saúde Coletiva, v. 22, n. 7, p. 2129-2133, jul. 2017.

66 ALMEIDA, Celia; CAMPOS, Rodrigo Pires de; BUSS, Paulo; FERREIRA, José Roberto; FONSECA, Luiz Eduardo. A concepção brasileira de cooperação Sul-Sul estruturante em saúde". Revista Eletrônica de Comunicação, Informação e Inovação em Saúde, Rio de Janeiro, v. 4, p. 25-35, mar. 2010.

${ }_{67}$ TORRONTEGUY, Marco Aurélio Antas. O direito humano à saúde no direito internacional: efetivação por meio da cooperação sanitária. 2010. Tese (Doutorado) - Faculdade de Direito Universidade de São Paulo, São Paulo, 2010 denominado posição na relação, reúne a perspectiva de horizontalidade na relação bilateral e a coordenação conjunta de programas e projetos de cooperação, anteriormente citadas. O segundo são os encargos financeiros, que ao questionarem quem arca com os custos da cooperação também informam sobre a existência de endividamento ou não. O terceiro é a necessidade de consenso para tornar públicos os documentos da cooperação. O quarto indicador de horizontalidade se refere aos mecanismos de consulta política, que reúnem tanto a necessidade de diálogo entre as partes para interpretar os tratados, elencadas por Torronteguy, e, para emendá-los, interpretada pelos autores do presente trabalho. O quinto é a sustentabilidade.

Para refletir sobre a legitimidade democrática, foram escolhidos dois indicadores: primeiro as formas de avaliação, que abrangem avaliação e monitoramento, elencadas por Torronteguy, e segundo, a triangulação, também elencada pelo autor, que reúne a perspectiva da triangulação, da obtenção de financiamento juntamente a outros atores, e a participação da sociedade civil organizada, representada pela presença ou não de Organizações Não Governamentais (ONG's). Enquanto a informação sobre a vigência fora respondida anteriormente neste estudo, os objetivos da cooperação serviram de base para a classificação dos regimes, e não foram observadas condicionalidades durante a análise qualitativa.

Quanto à seletividade, o que poderia chegar mais próximo desse indicador seria a ausência da Argentina no regime de fortalecimento institucional, que, por ser um país cujas dimensões, principalmente econômicas, estão mais próximas do Brasil que os demais, pode representar alguma interpretação de que o fortalecimento institucional seja dispensável — uma visão que pode ser duramente criticada se ele for encarado como troca e não como ajuda. Dessa forma, todos os indicadores pensados por Torronteguy ${ }^{68}$ foram absorvidos, de alguma maneira, pelo presente estudo.

Da seleção do primeiro grupo de categorias - a presença de instituições estruturantes e a ideia de fortalecimento das mesmas - resultou uma lição relevante: bebendo da mesma ideia do fortalecimento institucional está a ideia de fortalecimento setorial, que diferen-

68 TORRONTEGUY, Marco Aurélio Antas. O direito humano à saúde no direito internacional: efetivação por meio da cooperação sanitária. 2010. Tese (Doutorado) - Faculdade de Direito, Universidade de São Paulo, São Paulo, 2010. 
te do primeiro, no qual são agrupados atos que tratam do fortalecimento de uma instituição de maneira geral, trata de fortalecer instituições, ações ou programas, em uma matéria ou capacidade específica, por exemplo, um projeto para o fortalecimento em atenção integral e vigilância epidemiológica em DST/HIV/AIDS na Bolívia $^{69}$. O fortalecimento setorial permeia regimes nas seguintes dimensões:

TABELA 1 - Fortalecimento setorial em regimes bilaterais

Regime temático bilateral

Geral em matéria de saúde (23)

Fortalecimento institucional (18)

Saúde fronteiriça (13)

Farmacodependência (13)

Bancos de leite humano (11)

DST/HIV/Aids (10)

Previdência social (9)

Medicamentos e afins (6)

Saúde indígena (3)

Outros (23)

Fonte: autores

TABELA 2 - Fortalecimento setorial em regimes temáticos multilaterais

Regime temático multilateral

Redes de cooperação em saúde (9)

Medicamentos e afins (4)

Outros (3)

Fonte: autores

As tabelas, provavelmente, podem dizer mais do que lhes foi perguntado, mas elas somente são lições, quando reunidas sob a forma de respostas às perguntas anteriores à produção delas, quando servem a um fim. A identificação de um novo tipo de fortalecimento setorial — ensina sobre a capacidade de pulverização da cooperação estruturante em saúde, e também sobre a agenda que o Brasil realiza no âmbito da saúde internacional. Com base no exposto nas tabelas 1 e 2 , somado ao que é apresentado pela tabela a seguir, pode-se dizer que: 1. A cooperação estruturante em saúde transborda, de fato, aos demais regimes por meio de fortalecimento setorial; e 2. Ao incluir doenças específicas, notadamente as transmissíveis, o fortalecimento setorial implica a

\footnotetext{
69 Trata-se do Ajuste complementar ao Acordo Básico de Cooperação Técnica, Científica e Tecnológica entre o Governo da República Federativa do Brasil e o Governo do Estado Plurinacional da Bolívia para a implementação do projeto "Fortalecimento em atenção integral e vigilância epidemiológica em DST/HIV/AIDS na Bolívia.
}

realização de uma agenda mista - em parte preocupada com doenças específicas, que não são menos importantes, e em parte desenvolvendo novos modelos para tratar dos sistemas de saúde em longo prazo.

TABELA 3 - fortalecimento setorial e doenças: a agenda começa a se mostrar mista

\begin{tabular}{|c|c|c|c|c|}
\hline $\begin{array}{c}\text { Fortalecimento } \\
\text { institucional } \\
(18) \\
+ \\
\text { Redes de } \\
\text { cooperação em } \\
\text { saúde (9) }\end{array}$ & $\begin{array}{c}\text { Fortalecimento } \\
\text { setorial (50) }\end{array}$ & $\begin{array}{l}\text { Doenças } \\
(48)\end{array}$ & $\begin{array}{c}\text { Fortalecimento } \\
\text { setorial em } \\
\text { doenças (18) }\end{array}$ & $\begin{array}{c}\text { Fortalecimento } \\
\text { setorial em } \\
\text { doenças } \\
\text { transmissíveis } \\
(17)\end{array}$ \\
\hline $\begin{array}{l}18,62 \% \text { do } \\
\text { total do total } \\
\text { de atos que } \\
\text { compõem } \\
\text { regimes (145) }\end{array}$ & $\begin{array}{c}34,48 \% \\
\text { do total de } \\
\text { atos que } \\
\text { compõem } \\
\text { regimes }(145)\end{array}$ & \multirow[t]{2}{*}{$\begin{array}{l}33,1 \% \text { do } \\
\text { total de } \\
\text { atos que } \\
\text { compõem } \\
\text { regimes } \\
(145)\end{array}$} & $\begin{array}{l}12,41 \% \text { do } \\
\text { total de atos } \\
\text { que compõem } \\
\text { regimes }(145)\end{array}$ & $\begin{array}{l}11,72 \% \text { do } \\
\text { total de atos } \\
\text { que compõem } \\
\text { regimes (145) }\end{array}$ \\
\hline \multicolumn{2}{|c|}{$\begin{array}{c}\text { Juntos representam } 53,1 \% \\
\text { dos atos que compõem } \\
\text { regimes }(145)\end{array}$} & & $\begin{array}{l}36 \% \text { dos } \\
\text { atos de } \\
\text { fortalecimento } \\
\text { setorial }(50)\end{array}$ & $\begin{array}{c}34 \% \text { dos } \\
\text { atos de } \\
\text { fortalecimento } \\
\text { setorial (50) }\end{array}$ \\
\hline
\end{tabular}

Fonte: autores

Juntos, os regimes de Fortalecimento institucional e o de Redes de cooperação em saúde, somados aos atos de fortalecimento setorial pulverizados nos regimes, representam 53,1\% dos atos que compõem regimes, enquanto as Doenças se espalham por $33,1 \%$ dos atos que compõem regimes, incluindo as vezes em que são tratadas por meio de fortalecimento setorial, a exemplo do caso de 7 de 10 atos que compõem o regime de DST/ HIV/Aids. Dessa forma, a capacidade de pulverização do fortalecimento setorial equilibra a concentração do regime de Fortalecimento institucional no Uruguai, exposta no gráfico 2 .

Ainda, apesar de o regime de Saúde fronteiriça expor muito do que seria entendido como uma agenda Norte-Sul, ou vertical, de preocupação securitária sobre as epidemias, principalmente em atos internacionais mais antigos, mesmo assim, não são preocupações efêmeras, como são tipicamente as dessa agenda. A criação de Comissões Binacionais ${ }^{70}$ e Grupos de Trabalho ${ }^{71}$, destinados ao estudo continuado das questões de saúde na fronteira, confirmam isso.

Do segundo grupo de categorias, inspiradas na obra 70 Como faz o artigo I, inciso 1, do Ajuste complementar na área
de saúde ao Acordo básico de cooperação técnica, entre o Governo
da República Federativa do Brasil e o Governo da República Coop-
erativista da Guiana.
$71 \quad$ Como faz o artigo I, inciso 2, do Acordo interinstitucional in-
ternacional subscrito entre o Ministério da Saúde da República Fed-
erativa do Brasil e o Ministério da Saúde do Estado Plurinacional da
Bolívia em matéria de cooperação em saúde na fronteira. 
de Torronteguy ${ }^{72}$, que somente atingiram capacidade de tratamento nos regimes bilaterais, resultaram as seguintes tabelas. Capazes de inspirar algumas lições.

TABELA 4 - Indicadores de horizontalidade da cooperação internacional (parte 1)

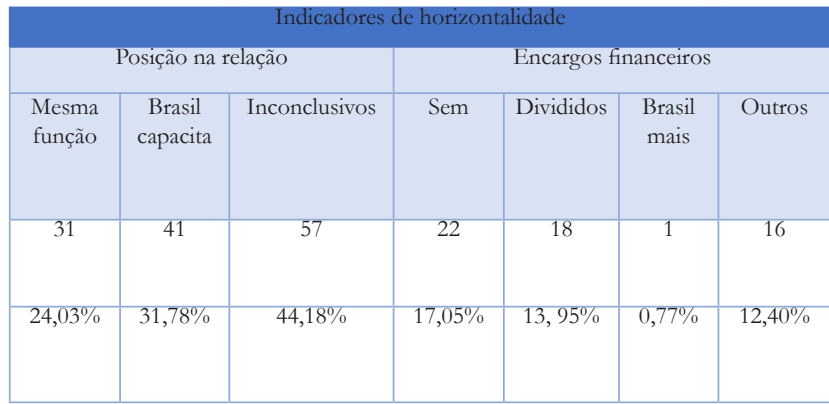

Fonte: autores

Sobre os indicadores de horizontalidade presentes na tabela 4, é possível verificar que, em termos de posição na relação, as quantias se aproximam, mas o Brasil ainda é mais provedor que parceiro de cooperação, apesar da pequena diferença entre o número de atos em que ele divide funções semelhantes com os parceiros, e da alta quantia de atos não considerados por serem inconclusivos, por tratarem de harmonização ou coordenação, sem direcionar especificamente qual ator deverá realizar cada ação.

Os encargos financeiros, nos atos em que foram positivados, também se equilibram, e o Brasil somente é responsável por todos os gastos em um ato internacional, enquanto os outros não possuem encargos financeiros, os compartilham entre os Estados ou, ainda, dependem de negociações futuras ou das disponibilidades orçamentárias em cada tempo. Mas é importante notar que, apenas, 57 dos 129 atos internacionais que foram conferidos positivavam a questão dos encargos financeiros de alguma forma, e que 22 deles informaram não haver tais encargos. Nesse contexto cabe relembrar a lição de Flávia Piovesan sobre os direitos sociais, econômicos e culturais, e a sua condição de programáticos, segundo a abordagem do Pacto Internacional sobre Direitos Econômicos, Sociais e Culturais, de 1966, que faz deles

direitos que demandam aplicação progressiva, já que não podem ser implementados sem que exista um mínimo de recursos econômicos disponível,

\footnotetext{
72 TORRONTEGUY, Marco Aurélio Antas. O direito humano à saúde no direito internacional: efetivação por meio da cooperação sanitária. 2010. 355 p. Tese (doutorado) - Faculdade de Direito, Universidade de São Paulo, São Paulo, 2010.
}

um mínimo de standard técnico-econômico, um mínimo de cooperação econômica internacional e, especialmente, uma prioridade na agenda política nacional. $^{73}$

TABELA 5 - Indicadores de horizontalidade da cooperação internacional (parte 2)

\begin{tabular}{|c|c|c|c|c|}
\hline $\begin{array}{c}\text { Consenso } \\
\text { para } \\
\text { divulgação }\end{array}$ & $\begin{array}{c}\text { Mecanismos de } \\
\text { consulta política }\end{array}$ & \multicolumn{3}{|c|}{ Sustentabilidade } \\
\hline Sim & Sim & Tipo 1 & Tipo 2 & Tipo 3 \\
\hline 61 & 82 & 1 & 19 & 9 \\
\hline $47,28 \%$ & $63,56 \%$ & $0,77 \%$ & $14,72 \%$ & $6,97 \%$ \\
\hline
\end{tabular}

Fonte: autores

Os indicadores, expostos na tabela 5, apresentam um cenário em que os atos que indicam a produção de relatórios para avaliação não chegam a metade dos atos que compõem regimes, mas todos que preveem algum tipo de publicação desses relatórios os vinculam à permissão explícita das Partes para a publicação dos mesmos. Uma grande quantidade de atos (63,56\%) possuem mecanismos de consulta política, ou seja, vinculam a produção de emendas ${ }^{74}$ e a resolução de dúvidas quanto à interpretação dos atos internacionais ${ }^{75}$, ao diálogo entre as partes.

A sustentabilidade parece ser, juntamente da baixa produção de relatórios e do difícil acesso a eles pelo público, uma das deficiências mas visíveis, e foi metodologicamente dividida em 3 tipos: o tipo 1 corresponde aos atos que versam unicamente sobre sustentabilidade, o tipo 2 são atos que versam sobre dar continuidade às atividades desenvolvidas por técnicos brasileiros no

PIOVESAN, Flávia. Direitos Humanos e o Direito Constitucional Internacional. 3. ed. atual. São Paulo: Max Limonad, 1997. p. 195.

${ }^{74}$ Como no caso do artigo VIII, inciso 2, do Ajuste complementar ao Acordo básico de cooperação científica e técnica entre o Governo da República Federativa do Brasil e o Governo da República Oriental do Uruguai para implementação do projeto "Apoio técnico para a expansão e consolidação da rede de bancos de leite humano do Uruguai".

75 Como no artigo VIII do Ajuste complementar ao Acordo básico de cooperação científica e técnica entre o Governo da República Federativa do Brasil e o Governo da República Oriental do Uruguai para implementação do projeto "Apoio técnico para a expansão e consolidação da rede de bancos de leite humano do Uruguai". 
país em questão ${ }^{76}$, o tipo 3 são atos que versam sobre sustentabilidade e sobre a questão da continuidade ao mesmo tempo, entre os 3 tipos, o segundo é o maior e menos horizontal deles.

TABELA 6 - Indicadores de preocupação com legitimidade democrática da cooperação internacional

\begin{tabular}{|c|c|c|c|c|c|}
\hline \multicolumn{5}{|c|}{ Indicadores de preocupação com a legitimidade democrática } \\
\hline Avaliação das atividades & \multicolumn{4}{|c|}{ Triangulação } \\
\hline Avaliação & Monitoramento & Sim & $\begin{array}{c}\text { Sim com } \\
\text { financiamento }\end{array}$ & $\begin{array}{c}\text { Com } \\
\text { ONG }\end{array}$ & $\begin{array}{c}\text { Com ONG e } \\
\text { financiamento }\end{array}$ \\
\hline 58 & 28 & 16 & 18 & 1 & 28 \\
\hline $44,96 \%$ & $21,70 \%$ & $12,40 \%$ & $13,95 \%$ & $0,77 \%$ & $21,70 \%$ \\
& & & & & \\
\hline
\end{tabular}

Fonte: autores

Os indicadores sobre preocupação com a legitimidade democrática expõem o seguinte: 86 atos internacionais preveem algum tipo de avaliação das atividades, mas, em apenas 28 deles, essas avaliações têm periodicidade, e, portanto, recebem o nome de monitoramento. Com relação à triangulação, os números demonstram que 34 atos internacionais consideram a participação de organizações e fundos internacionais, o que pode significar tanto algum grau de legitimidade democrática maior quanto de dependência. 29 atos internacionais consideram a possibilidade de participação de ONG's, o que pode representar tanto o aumento de acesso de entes não governamentais, e, portanto, da população, como a terceirização dos encargos estatais. Mas a resposta sobre o que realmente significam esses indicadores somente pode ser demonstrada por estudos de caso sobre regimes temáticos específicos e os processos causais, pelos quais eles nasceram e pelos quais eles se efetivam.

Por fim, a cooperação sul-americana em saúde, promovida pelo Brasil com os países da América do Sul, apresenta equilíbrio entre diversos indicadores, seja de horizontalidade, de legitimidade democrática, e de possibilidades estruturantes versus a tradicional cooperação para doenças específicas. A capacidade de pulverização da ideia de fortalecimento setorial é nítida e deve ser

\footnotetext{
${ }^{6}$ Como no artigo III, inciso 2, letra e, do Ajuste complementar ao Acordo básico de cooperação técnica entre o Governo da República Federativa do Brasil e o Governo da República do Equador para implementação do projeto "Apoio técnico para a expansão e consolidação da rede de bancos de leite humano no equador", e em outros atos internacionais.
}

valorizada, especialmente por demonstrar uma nova abordagem para doenças específicas. Assim, parece haver um processo de construção, tanto da presença de ideais Sul-Sul quanto do aumento das abordagens sustentáveis de fortalecimento. Uma construção que certamente precisa de atenção, e que não seguirá em frente sem ultrapassar diversos obstáculos atuais.

Cabe problematizar alguns pontos específicos das tabelas anteriores, que, em grande escala, se complementam. Por exemplo, o caso do consenso na publicidade dos relatórios produzidos, nos casos em que se prevê avaliação e monitoramento por meio de relatórios. Ocorre que esse consenso, apesar de demonstrar a horizontalidade entre os Estados, que precisam conceder permissão à divulgação, pouco confere à legitimidade democrática, devido ao fato de que a publicidade não é um fator considerado desde o início, e às vezes não é levada a cabo, relegando esses documentos ao desconhecimento total pela população que paga pela sua feitura ou elege representantes que votem pela sua extinção. Este é um ponto crucial quando se colocam em tela os rumos que a cooperação em saúde promovida pelo Brasil vem tomando.

Se, até 2017, o Brasil ainda firmava atos em matéria de saúde, e esta sobrevivia como um eixo importante da política externa, na atualidade, o contexto político brasileiro enfraqueceu um importante esquema cooperacional — que por não abranger as delimitações geográficas do presente estudo, não foi abordado aqui - mas que, segundo a literatura especializada, representa um aporte importante no âmbito da efetivação do direito humano à saúde, o Programa Mais Médicos. E, mais especificamente, um dos seus eixos, intitulado "Projeto Mais Médicos para o Brasil (PMMB)", voltado à provisão emergencial de médicos em áreas vulneráveis ${ }^{77}$, deixado por Cuba em novembro de 2018. Segundo Oliveira et al., "apenas com o Programa Mais Médicos que a provisão de médicos em áreas vulneráveis teve a magnitude e a resposta em tempo adequado para atender a demanda dos municípios brasileiros" ${ }^{\prime 78}$.

OLIVEIRA, Felipe Proenço de; VANNI, Tazio; PINTO, Hêider Aurélio; SANTOS, Jerzey Timoteo Ribeiro dos; FIGUEIREDO, Alexandre Medeiros de; ARAÚJO, Sidclei Queiroga de; MATOS, Mateus Falcão Martins; CYRINO, Eliana Goldfarb. Mais Médicos: um programa brasileiro em uma perspectiva internacional. Interface - Comunicação, Saúde, Educação, Botucatu, v. 19, n. 54, p. 623-634, jul./set. 2015.

78 OLIVEIRA, Felipe Proenço de; VANNI, Tazio; PINTO, Hêider Aurélio; SANTOS, Jerzey Timoteo Ribeiro dos; FIGUEIREDO, 
Ainda, os números sobre os indicadores de posição na relação, e os resultados pouco conclusivos sobre os encargos financeiros, presentes na tabela 4, somados à questão da ausência da Argentina no regime de fortalecimento institucional elencada com base no gráfico 2 , levam à necessidade de se discutirem as questões de poder e verticalidade nos esquemas de cooperação. Ocorre que, mesmo entre países em desenvolvimento, os motivos pelos quais os acordos são firmados, e os meios pelos quais tomam concretude, carecem de horizontalidade e legitimidade democrática. É nesse sentido que Torronteguy $^{79}$ desenvolve a ideia de uma verticalidade de meios para alcançar uma horizontalidade de fins, para racionalizar o cenário complexo que se apresenta na cooperação Sul-Sul: às vezes, a heterogeneidade dos países em desenvolvimento faz da verticalidade de meios, uma forma necessária à construção de capacidades, e, portanto, para atingir de fato a horizontalidade nas relações entre esses países.

Por outro lado, Dri e Pittas ${ }^{80}$ descrevem outro processo possível, verificado na cooperação em matéria de bancos de leite humano promovida pelo Brasil: em que a maneira pela qual se dá a prática da cooperação é capaz de efetivar um fim que poderia acabar sendo secundário. A política externa dos bancos de leite humano ilustra o cenário desse esquema cooperacional, que logra êxito tanto em termos de poder quanto de saúde global, devido ao fato de ser realizado em conformidade com valores de cooperação Sul-Sul.

Ainda, Buani ${ }^{81}$ busca compreender o intercâmbio de modelos e práticas em sociedades que passaram por conflitos armados recentes, identificando diversas dificuldades na construção e fortalecimento de instituições que sejam efetivas nessas sociedades fragilizadas. Em

$\overline{\text { Alexandre Medeiros de; ARAÚJO, Sidclei Queiroga de; MATOS, }}$ Mateus Falcão Martins; CYRINO, Eliana Goldfarb. Mais Médicos: um programa brasileiro em uma perspectiva internacional. Interface - Comunicação, Saúde, Educação, Botucatu, v. 19, n. 54, p. 623-634, jul./set. 2015. p. 623.

79 TORRONTEGUY, Marco Aurélio Antas. O direito humano à saúde no direito internacional: efetivação por meio da cooperação sanitária. 2010. Tese (Doutorado) - Faculdade de Direito Universidade de São Paulo, São Paulo, 2010.

80 DRI, Clarissa Franzoi; PITTAS, Tiago Mocellin. O diálogo entre saúde e política externa na cooperação brasileira em bancos de leite humano. Revista Ciência \& Saúde Coletiva, Rio de Janeiro, v. 22, n. 7, p. 2277-2286, jul. 2017.

81 BUANI, Christiani Amaral. A justiça de transição: ápice da internacionalização do direito? Revista de Direito Internacional, Brasília, v. 9, n, 4, p. 123-151, 2012. seu estudo, questões como o filtro cultural necessário nessas relações, e a falta de diálogo entre múltiplos modelos de inspiração importados, são centrais. Ao passo que, essa mesma ideia de colonialismo cultural e falta de diálogo horizontal é também demonstrada no estudo de Pereira $^{82}$, que trata da cooperação internacional entre juízes.

Os processos verificados nesses estudos na área da cooperação internacional e da internacionalização do direito confirmam o que já havia sido dito anteriormente neste trabalho: ainda é preciso conhecer mais sobre a concretude dos atos internacionais estudados, adentrando na segunda dimensão da cooperação estruturante e desmembrando os processos causais em seus contextos específicos, para compreender se a cooperação estruturante em saúde é, de fato, um modelo efetivo naquilo que se propõe.

\section{Considerações finais}

Neste trabalho foi proposta a divisão da cooperação estruturante em saúde em duas dimensões, ambas ligadas pelo tratado internacional e desenhadas para compreender a complexidade da mensuração da efetividade do direito internacional na contemporaneidade. Na primeira dimensão, a cooperação estruturante é a soma do reconhecimento de um problema e da construção de uma solução, passando por um processo político e resultando no ato internacional. Essa dimensão, permeada de variáveis como interesses e ideias, representa um input, pelo qual a demanda por cooperação surge, e o direito humano nasce. Na segunda dimensão, o ato internacional — surgido na primeira — para se tornar efetivo, é somado às instituições domésticas, e deve resultar em políticas públicas locais. Essa dimensão é como um output, onde o ato internacional desce ao nível doméstico para ser transformado em política pública — já que ele não é peça desse jogo — e o direito humano é emancipado, virando objeto de planos de ação concretos.

Essa transformação ocorre na medida em que, para ser efetivo, o direito internacional precisa penetrar na membrana estatal e interferir no âmbito doméstico. Se,

82 PEREIRA, Ruitemberg Nunes. Interações transjudiciais e transjudicialismo: sobre a linguagem irônica no direito internacional. Revista de Direito Internacional, Brasília, v. 9, n. 4, p. 169-199, 2012. 
na primeira dimensão, o direito internacional ainda é uma peça do tabuleiro internacional, sendo, portanto, ferramenta de Estados-nação, ele então necessita de alguma peça do tabuleiro doméstico que alcance os indivíduos, e essa peça é a política pública, que configura a segunda dimensão do direito internacional.

A relação entre o internacional e o doméstico, no caso da saúde global, já havia recebido ênfase anteriormente, nas palavras de Deisy Ventura, para quem,

\begin{abstract}
a consolidação de uma diplomacia solidária de saúde depende tanto da prevalência da ótica dos direitos humanos sobre interesses outros de nossa política externa, como da vontade política dos governos de completar o movimento iniciado com a reforma sanitária, construindo um sistema de saúde gratuito e de qualidade, como dever do Estado, direito de todos e baliza da ação internacional do Brasil ${ }^{83}$.
\end{abstract}

Assim, nesta pesquisa, foram investigados cerca de 4858 documentos de diversas plataformas oficiais que desenham o contorno da política externa brasileira, a fim de identificar os tratados internacionais capazes de estabelecer esquemas de cooperação internacional em matéria de saúde com os países da América do Sul. Nos 145 tratados selecionados para a investigação qualitativa, foram encontrados regimes temáticos dedicados à efetivação do direito humano à saúde, que buscam soluções para 31 problemas temáticos diferentes (bilaterais, incluindo o marcador "Outros", e multilaterais), além de regimes dedicados ao fortalecimento institucional e a redes de instituições estruturantes, e possibilidades de efetivação estruturante pulverizadas em outros regimes.

A análise qualitativa encontrou uma nova abordagem da cooperação regional, em construção, que apresenta uma agenda mista, mesclando o enfoque em doenças especificas e em fortalecimento institucional. Há ainda, novas empreitadas e perguntas disponíveis e pulsando com as condições políticas atuais do Brasil e do restante do globo.

Até onde esses regimes e possibilidades são exploradas, e o direito internacional descrito por Slaughter e Burke-White ${ }^{84}$ consegue penetrar a membrana doméstica por meio da cooperação internacional positivada

\footnotetext{
83 VENTURA, Deisy. Saúde pública e política externa brasileira. SUR - Revista Internacional de Direitos Humanos, São Paulo, v.10, n. 19, dez. 2013. p. 111

84 SLAUGHTER, Anne-Marie; BURKE-WHITE, William. The Future of International Law is Domestic (or, The European Way of Law). Harvard International Law Journal, Cambridge, v. 47, n. 2 , jun. 2006.
}

em atos internacionais, e se tornar de fato efetivo? Essa pergunta pode - e deve - ser feita mais de dez vezes, sobre mais de dez temáticas de saúde diferentes, por aqueles preocupados com o direito humano à saúde.

\section{Referências}

ALMEIDA, Celia. Saúde, política externa e cooperação sul-sul em saúde: elementos para a reflexão sobre o caso do Brasil. In: FUNDAÇÃO OSWALDO CRUZ. A saúde no Brasil em 2030 - prospecção estratégica do sistema de saúde brasileiro: desenvolvimento, Estado e politicas de saúde. Rio de Janeiro: Fiocruz/Ipea/Ministério da Saúde/ Secretaria de Assuntos Estratégicos da Presidência da República, 2013.

ALMEIDA, Celia; CAMPOS, Rodrigo Pires de; BUSS, Paulo; FERREIRA, José Roberto; FONSECA, Luiz Eduardo. A concepção brasileira de cooperação Sul-Sul estruturante em saúde". Revista Eletrônica de Comunicação, Informação e Inovação em Saúde, Rio de Janeiro, v. 4, p. 2535, mar. 2010.

BUANI, Christiani Amaral. A justiça de transição: ápice da internacionalização do direito? Revista de Direito Internacional, Brasília, v. 9, n, 4, p. 123-151, 2012.

BUCCI, Maria Paula Dallari. Buscando um conceito de políticas públicas para a concretização dos direitos humanos. Cadernos Pólis 2: Direitos Humanos e Politicas Públicas, São Paulo, Instituto Pólis, v. 2, p. 5-16, 2001.

BUSS, Paulo Marchiori; FERREIRA, José Roberto. Cooperação e integração regional em saúde na América do Sul: a contribuição da Unasul Saúde. Revista Ciência \& Saúde Coletiva, Rio de Janeiro, v. 16, n. 6, p. 2699-2711, jun. 2011.

BUSS, Paulo Marchiori; FONSECA, Luiz Eduardo. Diplomacia e cooperação em saúde: Uma perspectiva da Fiocruz. In: ALMINO, J; LIMA, S. E. M. (org.). 30 anos da $A B C$ : visões da cooperação técnica internacional brasileira. Brasilia: FUNAG, 2017.

DRI, Clarissa Franzoi. Demanda e oferta de bens públicos regionais: políticas públicas transnacionais na América do Sul? Revista de Iniciação Científica em Relaçôes Internacionais, João Pessoa, v. 3, n. 6, p. 1-8, 2016.

DRI, Clarissa Franzoi; PITTAS, Tiago Mocellin. O diálogo entre saúde e política externa na cooperação 
brasileira em bancos de leite humano. Revista Ciência \& Saúde Coletiva, Rio de Janeiro, v. 22, n. 7, p. 2277-2286, jul. 2017.

FERREIRA, José Roberto; FONSECA, Luiz Eduardo. Cooperação estruturante, a experiência da Fiocruz. Revista Ciência \& Saúde Coletiva, v. 22, n. 7, p. 2129-2133, jul. 2017.

GOODMAN, Ryan; JINKS, Derek. Measuring the Effects of Human Rights Treaties. European Journal of International Law, v. 14, n. 1, p. 171-183, 2003.

HALL, Peter Andrew. The role of interests, institutions, and ideas in the comparative political economy of industrialized nations. In: LICHBACK, M. ZUCKERMAN, A. (org.). Comparative politics: rationality, culture and structure. New York: Cambridge University Press, 1997.

IGREJA, Rebecca Lemos. O Direito como objeto de estudo empírico: o uso de métodos qualitativos no âmbito da pesquisa empírica em Direito. In: Machado, Maíra Rocha (org.). Pesquisar empiricamente o direito. São Paulo: Rede de Estudos Empíricos em Direito, 2017. p. 11-37.

KINGDON, John Wells. Juntando as coisas. In: SARAVIA, E. FERRAREZI, E. (org.). Políticas Públicas - Coletânea. Brasília: ENAP, 2006. p. 225-246. v. 1.

LUCAS, Doglas Cesar. Multiculturalismo e o debate entre liberais e comunitaristas: em defesa da Interculturalidade dos Direitos Humanos. Revista Sequência, Florianópolis, v. 30, n. 58, p. 101-130, jul. 2009.

OLIVEIRA, Felipe Proenço de; VANNI, Tazio; PINTO, Hêider Aurélio.; SANTOS, Jerzey Timoteo Ribeiro dos; FIGUEIREDO, Alexandre Medeiros de; ARAÚJO, Sidclei Queiroga de; MATOS, Mateus Falcão Martins; CYRINO, Eliana Goldfarb. Mais Médicos: um programa brasileiro em uma perspectiva internacional. Interface - Comunicação, Saúde, Educação, Botucatu, v. 19, n. 54, p. 623-634, jul./set. 2015.

PALIER, Bruno; SUREL, Yves. Les Trois I et l'analyse de l'Etat em action. Revue française de science politique, Paris, v. 55, n. 1, p. 7-32, 2005.

PEREIRA, Ruitemberg Nunes. Interações transjudiciais e transjudicialismo: sobre a linguagem irônica no direito internacional. Revista de Direito Internacional, Brasília, v. 9, n. 4, p. 169-199, 2012.

PIOVESAN, Flávia. Direitos Humanos e o Direito Constitucional Internacional. 3. ed. atual. São Paulo: Max Limonad,
1997.

PITTAS, Tiago Mocellin. O estado da cooperação em saúde: Brasil, Mercosul e Unasul. Revista de Iniciação Científica em Relações Internacionais, João Pessoa, v. 3, n. 6, p. 138-162, 2016.

POZZATTTI JÚNIOR, Ademar. Cooperação Internacional como Acesso à Justiça nas Relações Internacionais: os desafios do direito brasileiro para a implementação de uma cultura cosmopolita. 2015. 529 p. Tese (Doutorado) - Programa de PósGraduação em Direito, Universidade Federal de Santa Catarina, Florianópolis, 2015.

POZZATTI JÚNIOR, Ademar. O direito internacional entre o dever ético e a ação política: os fundamentos de um dever de cooperação internacional na filosofia política de Immanuel Kant. Revista de Direito Internacional, Brasília, v. 13, n. 3, p. 405-421, 2016.

SLAUGHTER, Anne-Marie; BURKE-WHITE, William. The Future of International Law is Domestic (or, The European Way of Law). Harvard International Law Journal, Cambridge, v. 47, n. 2, jun. 2006.

TORRONTEGUY, Marco Aurélio Antas. O direito bumano à saúde no direito internacional: efetivação por meio da cooperação sanitária. 2010. Tese (Doutorado) - Faculdade de Direito, Universidade de São Paulo, São Paulo, 2010.

UNIÃO DAS NAÇÕES SUL-AMERICANAS. Consejo de Salud. Resolución 07/2009. Guayaquil, Ecuador, 24 nov. 2009. Disponível em: http://www.rets.epsjv. fiocruz.br/sites/default/files/arquivos/unasul-saude_ res072009.pdf Acesso em: 05 jun. 2019.

VARELLA, Marcelo Dias. Internacionalização do Direito: superação do paradigma estatal e a insuficiência de estruturas de diálogos. Revista de Direito Internacional, Brasília, v. 9, n. 4, p. 1-5, 2012.

VENTURA, Deisy. Saúde pública e política externa brasileira. SUR - Revista Internacional de Direitos Humanos, São Paulo, v.10, n. 19, dez. 2013.

VIGEVANI, Tullo; RAMANZINI JUNIOR, Haroldo. Autonomia, integração regional e Política Externa Brasileira: Mercosul e Unasul. Dados - Revista de Ciências Sociais, Rio de Janeiro, v. 57, n. 2, p. 517-552, abr./jun. 2014.

YIN, Robert. Estudo de caso: planejamento e métodos. 2. ed. Porto Alegre: Bookman, 2001. 
Para publicar na Revista de Direito Internacional, acesse o endereço eletrônico www.rdi.uniceub.br ou www.brazilianjournal.org.

Observe as normas de publicação, para facilitar e agilizar o trabalho de edição. 